BMC

Genomics

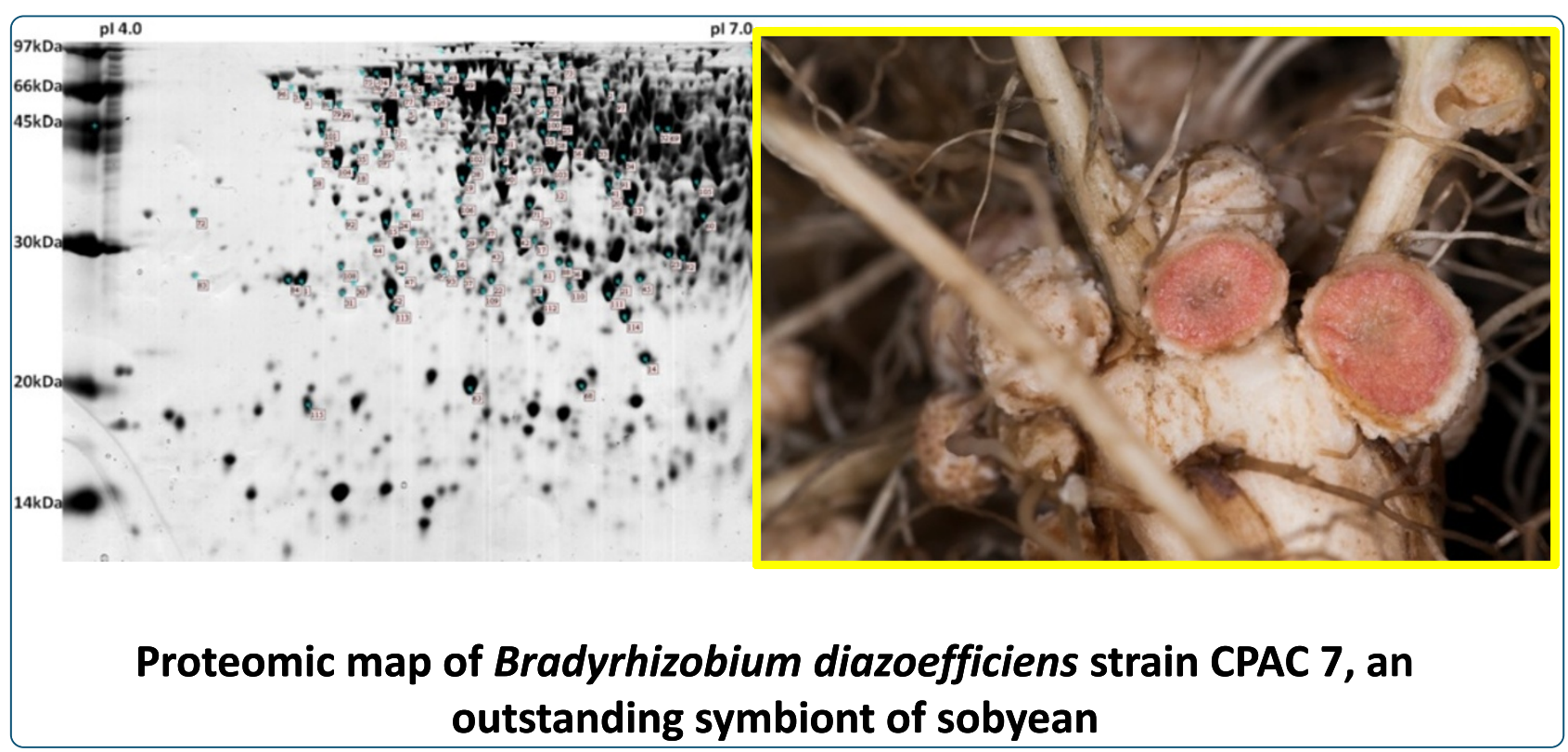

Proteomic analysis of free-living Bradyrhizobium diazoefficiens: highlighting potential determinants of a successful symbiosis

Gomes et al.

C Biomed Central 


\title{
Proteomic analysis of free-living Bradyrhizobium diazoefficiens: highlighting potential determinants of a successful symbiosis
}

\author{
Douglas Fabiano Gomes ${ }^{1,2}$, Jesiane Stefânia da Silva Batista1,3 , Amanda Alves Paiva Rolla', \\ Luciano Paulino da Silva ${ }^{4}$, Carlos Bloch ${ }^{4}$, Lygia Vitoria Galli-Terasawa ${ }^{2}$ and Mariangela Hungria ${ }^{* *}$
}

\begin{abstract}
Background: Strain CPAC 7 (=SEMIA 5080) was recently reclassified into the new species Bradyrhizobium diazoefficiens; due to its outstanding efficiency in fixing nitrogen, it has been used in commercial inoculants for application to crops of soybean [Glycine max (L.) Merr.] in Brazil and other South American countries. Although the efficiency of $B$. diazoefficiens inoculant strains is well recognized, few data on their protein expression are available.

Results: We provided a two-dimensional proteomic reference map of CPAC 7 obtained under free-living conditions, with the successful identification of 115 spots, representing 95 different proteins. The results highlighted the expression of molecular determinants potentially related to symbiosis establishment (e.g. inositol monophosphatase, IMPase), fixation of atmospheric nitrogen $\left(\mathrm{N}_{2}\right)$ (e.g. NifH) and defenses against stresses (e.g. chaperones). By using bioinformatic tools, it was possible to attribute probable functions to ten hypothetical proteins. For another ten proteins classified as "NO related COG" group, we analyzed by RT-qPCR the relative expression of their coding-genes in response to the nodulation-gene inducer genistein. Six of these genes were up-regulated, including blr0227, which may be related to polyhydroxybutyrate (PHB) biosynthesis and competitiveness for nodulation.
\end{abstract}

Conclusions: The proteomic map contributed to the identification of several proteins of $B$. diazoefficiens under free-living conditions and our approach—combining bioinformatics and gene-expression assays — resulted in new information about unknown genes that might play important roles in the establishment of the symbiosis with soybean.

Keywords: Symbiosis, Nitrogen fixation, Two-dimensional proteomics, RT-qPCR, Bradyrhizobium

\section{Background}

Biological $\mathrm{N}_{2}$ fixation (BNF) is a fundamental component of the global nitrogen $(\mathrm{N})$ cycle, both in natural and agricultural environments. The symbiosis of legumes with soil-borne symbiotic $\mathrm{N}_{2}$-fixing bacteria, which are frequently referred to as rhizobia, can often provide more than $60 \%$ of the plant's $\mathrm{N}$ requirements [1,2]. Regarding the concept of agriculture sustainability, BNF contributes to the improvement of food production without cultivation of new lands, to lowering input costs for the farmers and to mitigating environmental degradation. Such benefits occur when BNF replaces chemical N-fertilizers, which

\footnotetext{
* Correspondence: mariangela.hungria@embrapa.br

'Embrapa Soja, Embrapa Soja, C.P. 231, 86001-970 Londrina, Paraná, Brazil

Full list of author information is available at the end of the article
}

are expensive, and, among other harmful environment impacts, foment greenhouse-gas emissions [3,4].

Cultivation of soybean [Glycine max (L.) Merr.] has increased globally, mainly due to its high protein and oil contents, and plant breeding has resulted in increasing yields [5]. Certainly, efficient BNF is a major contributor to the achievement of high yields with low input costs [6]. An important example is the contribution of BNF to soybean cropping in Brazil, associated with application to the seeds at sowing of inoculants containing elite strains of Bradyrhizobium, including CPAC 15 (=SEMIA 5079) and CPAC 7 (=SEMIA 5080) [7,8]. The combination of these strains can fulfill much of the crop's $\mathrm{N}$ needs, resulting in estimated savings of about US \$15 billion in N-fertilizers per cropping season [9].

\section{() Biomed Central}

(c) 2014 Gomes et al.; licensee BioMed Central Ltd. This is an Open Access article distributed under the terms of the Creative Commons Attribution License (http://creativecommons.org/licenses/by/4.0), which permits unrestricted use, distribution, and reproduction in any medium, provided the original work is properly credited. The Creative Commons Public Domain Dedication waiver (http://creativecommons.org/publicdomain/zero/1.0/) applies to the data made available in this article, unless otherwise stated. 
Bradyrhizobium diazoefficiens was recently reclassified as a novel species on the bases of morpho-physiological, genotypic and genomic differences from Bradyrhizobium japonicum [10]. Strain CPAC 7 (=SEMIA 5080) has outstanding efficiency in fixing $\mathrm{N}_{2}$ with soybean and good adaptation to the often-stressful edaphoclimatic conditions of the tropics $[11,12]$. These features are responsible for the inclusion of this strain in inoculants applied to soybean in Brazil since 1992 [7,9].

The type strain of $B$. diazoefficiens, USDA $110^{\mathrm{T}}$ has had its genome elucidated; however, of the 8,317 potential protein-encoding genes, $30 \%$ were assigned as hypothetical and $18 \%$ showed no similarity to any known gene [13]. Later, the expression of several predicted proteincoding genes in USDA $110^{\mathrm{T}}$ was reported in transcriptomic and proteomic studies [14-19]. Nevertheless, despite the economic importance of $B$. diazoefficiens as a component of soybean inoculants worldwide $[9,10]$, few data are available on the proteins it synthesizes in the free-living state. It is well known that major attributes of successful elite strains, such as saprophytic competence, adaptation to stressful conditions and nodulation competitiveness must be expressed when free-living.

Our research group has just completed the genome sequencing of strain CPAC 7 [20] and, as occurred with USDA 110 [13], it was not possible to attribute functions to about $50 \%$ of the genes. Therefore, the establishment of a proteomic reference map for this strain in the free-living state can both add valuable protein-expression data to the genomic-annotation process [21-23] and help to attribute probable functions to hypothetical proteins $[21,23]$.

Here we present the first two-dimensional proteomic reference map for free-living $B$. diazoefficiens strain CPAC 7 , emphasizing molecular determinants of symbiosisestablishment and of tolerance of environmental stresses. Additionally, we ascribe putative functions to some hypothetical proteins detected at the proteomic level. For other hypothetical proteins without available information, we analyzed the relative expression of their coding-genes in response to the main soybean-nodulation-inducing molecule, the flavonoid genistein.

\section{Results and discussion}

\section{Two-dimensional gel electrophoresis and protein} identification

In studies with two-dimensional gels, it is necessary to optimize the resolution of the protein maps as a function of the nature and characteristics of the samples studied. With this goal, a previous experiment to obtain an overview of the protein distribution of $B$. diazoefficiens strain CPAC 7 was carried out with a broad-range IPG strip ( $\mathrm{pH} 3-10)$ for the first-dimensional protein separation. After SDS-PAGE, the results showed that most of protein spots remained clustered in the $\mathrm{pI}$ range of $\mathrm{pH}$ 5-7 (data not shown). To improve the separation of the proteins, we then employed in the first-dimension electrophoresis IPG strips with a narrower $\mathrm{pH}$ range ( $\mathrm{pH} 4-7)$, that confirmed, in triplicated gels, better resolution than the strips with pH 3-10.

Using computer-assisted gel-image analysis software, well-defined spots were detected and the majority of their molecular weights ranged between $14 \mathrm{kDa}$ and $97 \mathrm{kDa}$ (Figure 1). Among these, 150 spots were selected and analyzed by MALDI-TOF MS or, when necessary, by MS/MS. Mass spectra of peptide fragments were compared with database entries, regarding the statistical requirements, and 115 spots were successfully identified, representing 95 different proteins (Tables 1 and 2). Information on the spectrometry data set is available in Additional file 1: Table S1. The presence of distinct spots for the same protein may be the result of posttranslational modifications.

\section{Protein functional classification and cellular location}

According to the functional classification in COG, proteins were distributed in 16 categories, belonging to four functional groups (Figure 2). In the metabolism-related functional group, there were eight categories, comprising the greatest number of experimentally identified proteins $(40 \%)$. Next, $21 \%$ of the proteins were clustered in three functional categories related to information storage and processing, while the cellular-processes signaling group encompassed $13 \%$ of the proteins distributed in three categories. Finally, seven proteins were pooled in two other categories of a poorly characterized group, and 20 proteins did not fit any of the COG categories, being assigned as "not in COG" (Figure 2).

The high percentage of proteins with metabolic functions in CPAC 7 (Figure 2) is consistent with rhizobia's ability to adapt to varied edaphoclimatic conditions. Several of these proteins are related to energy metabolism, e.g. succinate dehydrogenase flavoprotein subunit and malate dehydrogenase, which participate in the tricarboxylic acid (TCA) cycle, the main pathway for obtaining energy and also important in the synthesis of precursors of the biosynthesis of amino acids, purines, pyrimidines and vitamins [23].

Proteins associated with amino-acid and lipid metabolism may be particularly important for free-living cells, and several of those proteins identified in CPAC 7 have been previously reported in B. japonicum CPAC 15 [23]. Beyond their main functions, proteins in these two categories may also play important roles at various stages of the symbiotic interaction, since auxotrophic mutants in both of them are defective in both nodulation and in $\mathrm{N}_{2}$-fixation abilities [24].

The second largest functional group-information storage and processing (Figure 2)-encompassed several transcriptional and translational factors (Table 1). These proteins have fundamental roles in controlling metabolic pathways because they regulate and ensure the accuracy 


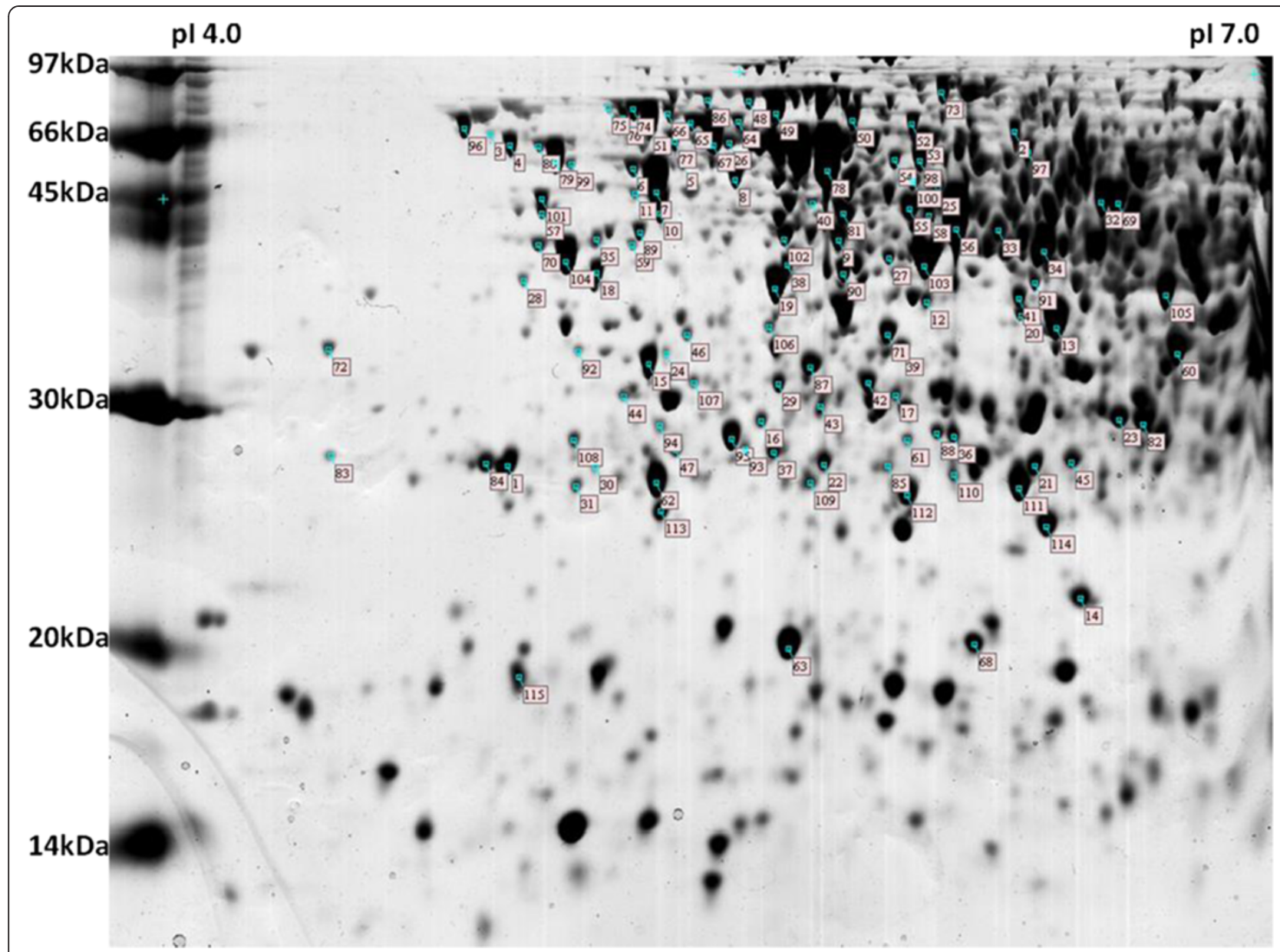

Figure 1 Two-dimensional electrophoresis protein profile of Bradyrhizobium diazoefficiens CPAC 7 whole cell extract at free-living state.

More information about expressed proteins is available in Tables 1 and 2.

of gene expression [25]; furthermore, under stress conditions they can also perform as chaperonins, helping in $d e$ novo protein folding and preventing damaged proteins from forming aggregates [26,27].

Most proteins belonging to the cellular-processes-andsignaling functional category were correlated with defense against stressful conditions (Table 1). Mechanisms of response to stresses are usually conserved among bacterial species, and required for rapid adaptation to environmental and metabolic changes. One of these responses comprises the expression of molecular chaperones, such as DnaK, GrpE and, GroEL [28], all of which were detected in our study (Table 1). Also related to the mediation of adaptive responses to adverse conditions [29,30], two Clp proteases, $\mathrm{ClpB}$ and $\mathrm{ClpX}$, were expressed in $B$. diazoefficiens CPAC 7. Finally, there was a cytoplasmic protein member of the two component response regulator OmpR family; proteins of this family are amongst the best characterized bacterial positive regulators, improving the transcriptional capacity of RNA polymerase, with reported effects in osmoregulation in Escherichia coli [31].
The cellular locations of all 115 identified proteins, predicted by PSORT-B and PSLpred, are listed in Tables 1 and 2. Although the majority of the proteins extracted in our study are located in cell cytoplasm and periplasm, two inner-membrane and one extracellular protein were obtained. Similar results have been reported in previous rhizobial proteomic studies by our group [23,32].

\section{Symbiosis establishment and $\mathrm{N}_{2}$-fixation-related proteins}

In the establishment of the legume-rhizobia symbiosis, an exchange of molecular signals starts with the host plant's release of molecules, mainly flavonoids, that induce expression of rhizobial nodulation (nod) genes. The products of nod-genes, the Nod factors (lipo-chitin oligosaccharides, LCOs), play critical roles in root nodulation [33]. Host specificity is also determined by the Nod factors, by means of the incorporation of $\alpha, \beta$-unsaturated acyl chains in the backbone structure [34]. In our proteomic reference map, we identified one acyl carrier protein, 3-oxoacyl-ACP synthase, and one ACP S-malonyl transferase (Table 2), both required for the synthesis of essential fatty acyl chains. 
Table 1 Identified proteins of Bradyrhizobium diazoefficiens CPAC 7 whole cell extract and classification according to COG

\begin{tabular}{|c|c|c|c|c|c|c|c|}
\hline Spot ID & Gene & Product & NCBI ID & Cellular location & ${ }^{*} \mathrm{~T} /{ }^{* *} \mathrm{E} \mathrm{pl}$ & ${ }^{*} \mathrm{~T} /{ }^{* *} \mathrm{E} M W$ & Organism \\
\hline \multicolumn{8}{|c|}{ Metabolism } \\
\hline \multicolumn{8}{|c|}{ Energy production and conversion } \\
\hline 1 & nuoC & NADH dehydrogenase subunit $C$ & gi|27380028 & Cytoplasmic & $4.88 / 4.94$ & $23201 / 27000$ & B. diazoefficiens USDA 110 \\
\hline 2 & $\operatorname{sdh} A$ & Succinate dehydrogenase flavoprotein subunit & gi|27375625 & Periplasmic & $5.91 / 6.34$ & $66903 / 70000$ & B. diazoefficiens USDA 110 \\
\hline 3 & $p d h B$ & Pyruvate dehydrogenase subunit beta & gi|27379893 & Cytoplasmic & $4.81 / 4.90$ & $48906 / 65000$ & B. diazoefficiens USDA 110 \\
\hline 4 & $p d h B$ & Pyruvate dehydrogenase subunit beta & gi|27379893 & Cytoplasmic & $4.81 / 4.95$ & $48906 / 65000$ & B. diazoefficiens USDA 110 \\
\hline 5 & $a t p D$ & ATP synthase FOF1 subunit beta & gi|27375551 & Cytoplasmic & $5.13 / 5.42$ & $50987 / 62000$ & B. diazoefficiens USDA 110 \\
\hline 6 & $a t p D$ & ATP synthase FOF1 subunit beta & gi|27375552 & Cytoplasmic & $5.13 / 5.28$ & $50987 / 62000$ & B. diazoefficiens USDA 110 \\
\hline 7 & $a t p D$ & ATP synthase FOF1 subunit beta & gi|27375551 & Cytoplasmic & $5.13 / 5.35$ & $50987 / 57000$ & B. diazoefficiens USDA 110 \\
\hline 8 & & Aldehyde dehydrogenase & gi|27379895 & Cytoplasmic & $6.04 / 5.57$ & $55297 / 60000$ & B. diazoefficiens USDA 110 \\
\hline 9 & & Succinate-semialdehyde dehydrogenase & gi|27379109 & Cytoplasmic & $5.3 / 5.86$ & $50087 / 51000$ & B. diazoefficiens USDA 110 \\
\hline 10 & eno & Phosphopyruvate hydratase & gi|27379905 & Cytoplasmic & $5.08 / 5.36$ & $45314 / 53000$ & B. diazoefficiens USDA 110 \\
\hline 11 & eno & Phosphopyruvate hydratase & gi|27379905 & Cytoplasmic & $5.08 / 5.28$ & $45314 / 55000$ & B. diazoefficiens USDA 110 \\
\hline 12 & $m d h$ & Malate dehydrogenase & gi|384214148 & Cytoplasmic & $5.88 / 6.09$ & $34259 / 41000$ & B. japonicum USDA 6 \\
\hline 13 & $m d h$ & Malate dehydrogenase & gi|27375567 & Cytoplasmic & $5.88 / 6.09$ & $34275 / 41000$ & B. diazoefficiens USDA 110 \\
\hline 14 & & Rieske iron-sulfur protein & gi|354959910 & Cytoplasmic & $5.9 / 6.52$ & $15192 / 22000$ & B. japonicum USDA 6 \\
\hline 15 & etfl & Electron transfer flavoprotein large subunit & gi|27376489 & Cytoplasmic & $5.14 / 5.33$ & $32186 / 34000$ & B. diazoefficiens USDA 110 \\
\hline 16 & & Ferredoxin NADP + reductase & gi|27375211 & Cytoplasmic & $5.54 / 5.64$ & $31764 / 29000$ & B. diazoefficiens USDA 110 \\
\hline \multicolumn{8}{|c|}{ Carbohydrate transport and metabolism } \\
\hline 17 & & Inositol monophosphatase & gi|27382842 & Cytoplasmic & $5.61 / 6.02$ & $28290 / 31000$ & B. diazoefficiens USDA 110 \\
\hline 18 & & Sugar kinase & gi|27375915 & Cytoplasmic & $5.06 / 5.20$ & $35336 / 38000$ & B. diazoefficiens USDA 110 \\
\hline 19 & & Sugar $A B C$ transporter substrate-binding protein & gi|27378319 & Periplasmic & $5.63 / 5.68$ & $38378 / 38000$ & B. diazoefficiens USDA 110 \\
\hline 20 & & 6-Phosphogluconate dehydrogenase & gi|27381870 & Cytoplasmic & $5.88 / 6.35$ & $35880 / 36000$ & B. diazoefficiens USDA 110 \\
\hline \multicolumn{8}{|c|}{ Amino acid transport and metabolism } \\
\hline 21 & $\operatorname{trpF}$ & $\mathrm{N}$-(5'-phosphoribosyl)anthranilate isomerase & gi|27375855 & Cytoplasmic & $5.82 / 6.36$ & $23966 / 27000$ & B. diazoefficiens USDA 110 \\
\hline 22 & leuD & Isopropylmalate isomerase small subunit & gi|27375606 & Cytoplasmic & $5.52 / 5.74$ & $22781 / 27000$ & B. diazoefficiens USDA 110 \\
\hline 23 & & Amino acid $A B C$ transporter substrate-binding protein & gi|27379557 & Periplasmic & $6.21 / 6.60$ & $36860 / 30000$ & B. diazoefficiens USDA 110 \\
\hline 24 & dapF & Diaminopimelate epimerase & gi|27375588 & Cytoplasmic & $5.09 / 5.30$ & $31803 / 33000$ & B. diazoefficiens USDA 110 \\
\hline 26 & $g \ln A$ & Glutamine synthetase & gi|27380060 & Cytoplasmic & $5.44 / 5.47$ & $52623 / 66000$ & B. diazoefficiens USDA 110 \\
\hline 27 & & L-asparaginase & gi|27380061 & Periplasmic & $5.93 / 5.93$ & $39549 / 40000$ & B. diazoefficiens USDA 110 \\
\hline 28 & $\operatorname{ser} B$ & Phosphoserine phosphatase & gi|27381616 & Cytoplasmic & $4.83 / 4.93$ & $32322 / 39000$ & B. diazoefficiens USDA 110 \\
\hline 29 & $\arg B$ & Acetylglutamate kinase & gi|27383212 & Cytoplasmic & $5.33 / 5.60$ & $31294 / 32000$ & B. diazoefficiens USDA 110 \\
\hline
\end{tabular}


Table 1 Identified proteins of Bradyrhizobium diazoefficiens CPAC 7 whole cell extract and classification according to COG (Continued)

\begin{tabular}{|c|c|c|c|c|c|c|c|}
\hline \multicolumn{8}{|c|}{ Coenzyme transport and metabolism } \\
\hline 31 & thiE & Thiamine-phosphate pyrophosphorylase & gi|27381769 & Cytoplasmic & $4.99 / 5.06$ & $22484 / 26000$ & B. diazoefficiens USDA 110 \\
\hline 32 & ahcy & S-Adenosyl-L-homocysteine hydrolase & gi|27381055 & Cytoplasmic & $6.00 / 6.55$ & $52318 / 45000$ & B. diazoefficiens USDA 110 \\
\hline 33 & metk & S-Adenosylmethionine synthetase & gi|27381056 & Cytoplasmic & $5.88 / 6.25$ & $43613 / 42000$ & B. diazoefficiens USDA 110 \\
\hline 34 & metk & S-Adenosylmethionine synthetase & gi|27381056 & Cytoplasmic & $5.88 / 6.38$ & $43613 / 41000$ & B. diazoefficiens USDA 110 \\
\hline 35 & $\operatorname{hem} B$ & Delta-aminolevulinic acid dehydratase/Porphobilinogen synthase & gi|1170210 & Cytoplasmic & $4.99 / 5.11$ & $38843 / 42000$ & B. diazoefficiens USDA 110 \\
\hline \multicolumn{8}{|c|}{ Nucleotide transport and metabolism } \\
\hline 38 & hemH & Phosphoribosylaminoimidazole-succinocarboxamide synthase & gi|27375923 & Cytoplasmic & $5.35 / 5.64$ & $33736 / 40000$ & B. diazoefficiens USDA 110 \\
\hline 39 & hemH & Phosphoribosylaminoimidazole-succinocarboxamide synthase & gi|27375923 & Cytoplasmic & $5.35 / 5.90$ & $33736 / 34000$ & B. diazoefficiens USDA 110 \\
\hline \multicolumn{8}{|c|}{ Lipid transport and metabolism } \\
\hline 40 & & 3-Oxoacyl-ACP synthase & gi|27378919 & Cytoplasmic & $5.56 / 5.71$ & $44874 / 45000$ & B. diazoefficiens USDA 110 \\
\hline 41 & $i s p H$ & 4-Hydroxy-3-methylbut-2-enyl diphosphate reductase & gi|27376425 & Cytoplasmic & $5.75 / 6.3$ & $35239 / 37000$ & B. diazoefficiens USDA 110 \\
\hline 42 & $f a b D$ & Nitrogenase iron protein ACP S-malonyl transferase & gi|27379193 & Cytoplasmic & $5.57 / 5.87$ & $32462 / 32000$ & B. diazoefficiens USDA 110 \\
\hline 43 & $f a d B$ & Enoyl CoA hydratase & gi|27378147 & Cytoplasmic & $5.44 / 5.73$ & $27829 / 30000$ & B. diazoefficiens USDA 110 \\
\hline 44 & Ipk & 4-Diphosphocytidyl-2-C-methyl-D-erythritol kinase & gi|27377637 & Cytoplasmic & $5.03 / 5.19$ & $31076 / 31000$ & B. diazoefficiens USDA 110 \\
\hline \multicolumn{8}{|c|}{ Inorganic ion transport and metabolism } \\
\hline 45 & $\bmod A$ & $\mathrm{ABC}$ transporter molybdenum-binding protein & gi|27383271 & Periplasmic & $6.62 / 6.46$ & $27290 / 27000$ & B. diazoefficiens USDA 110 \\
\hline 46 & nifH & Nitrogenase iron protein & gi|128264 & Cytoplasmic & $5.03 / 5.36$ & $31902 / 35000$ & B. diazoefficiens USDA 110 \\
\hline \multicolumn{8}{|c|}{ Secondary metabolites biosynthesis, transport and catabolism } \\
\hline 47 & & Thiol oxidoreductase FrnE & gi|27380891 & Cytoplasmic & $5.1 / 5.33$ & $24357 / 28000$ & B. diazoefficiens USDA 110 \\
\hline \multicolumn{8}{|c|}{ Information storage and processing } \\
\hline \multicolumn{8}{|c|}{ Translation, ribosomal structure and biogenesis } \\
\hline 48 & fusA & Elongation factor $\mathrm{G}$ & gi|27380514 & Cytoplasmic & $5.32 / 5.52$ & $76067 / 84000$ & B. diazoefficiens USDA 110 \\
\hline 49 & fusA & Elongation factor $G$ & gi|27380514 & Cytoplasmic & $5.32 / 5.60$ & $76067 / 81000$ & B. diazoefficiens USDA 110 \\
\hline 50 & typA & GTP-binding tyrosin phosphorylated protein & gi|27375651 & Cytoplasmic & $5.49 / 5.82$ & $67131 / 74000$ & B. diazoefficiens USDA 110 \\
\hline 51 & typA & GTP-binding tyrosin phosphorylated protein & gi|27375651 & Cytoplasmic & $5.49 / 5.26$ & $67131 / 72000$ & B. diazoefficiens USDA 110 \\
\hline 52 & asps & Aspartyl-tRNA synthetase & gi|27379254 & Cytoplasmic & $5.71 / 6.00$ & $66989 / 73000$ & B. diazoefficiens USDA 110 \\
\hline 53 & & Transporter ATP-binding protein & gi|27381796 & Inner-membrane & $5.58 / 6.00$ & $61850 / 67000$ & B. diazoefficiens USDA 110 \\
\hline 54 & gatA & Aspartyl/glutamyl-tRNA amidotransferase subunit A & gi|13470863 & Cytoplasmic & $5.66 / 5.95$ & $55801 / 59000$ & Mesorhizobium loti MAFF303099 \\
\hline 55 & tuf & Elongation factor Tu & gi|27380513 & Cytoplasmic & $5.78 / 5.99$ & $43569 / 44000$ & B. diazoefficiens USDA 110 \\
\hline 56 & tuf & Elongation factor Tu & gi|27380513 & Cytoplasmic & $5.79 / 6.12$ & $43569 / 43000$ & B. diazoefficiens USDA 110 \\
\hline 57 & tuf & Elongation factor Tu & gi|27380513 & Cytoplasmic & $5.78 / 5.00$ & $43569 / 42000$ & B. diazoefficiens USDA 110 \\
\hline 58 & tuf & Elongation factor Tu & gi|27380513 & Cytoplasmic & $5.79 / 6.05$ & $43569 / 43000$ & B. diazoefficiens USDA 110 \\
\hline
\end{tabular}


Table 1 Identified proteins of Bradyrhizobium diazoefficiens CPAC 7 whole cell extract and classification according to COG (Continued)

\begin{tabular}{|c|c|c|c|c|c|c|c|}
\hline 59 & hisZ & ATP phosphoribosyltransferase & gi|27382635 & Cytoplasmic & $5.1 / 5.22$ & $41078 / 41000$ & B. diazoefficiens USDA 110 \\
\hline 60 & & Elongation factor Ts & gi|27379971 & Cytoplasmic & $6.17 / 6.77$ & $32175 / 33000$ & B. diazoefficiens USDA 110 \\
\hline 61 & & Sigma-54 modulation protein & gi|27375835 & Cytoplasmic & $5.62 / 5.97$ & $21727 / 29000$ & B. diazoefficiens USDA 110 \\
\hline 62 & rpll & $50 S$ ribosomal protein L9 & gi|27379187 & Cytoplasmic & $5.08 / 5.22$ & $21886 / 26000$ & B. diazoefficiens USDA 110 \\
\hline 63 & $r p s F$ & ACP S-malonyltransferase & gi|27379190 & Cytoplasmic & $5.46 / 5.64$ & $18616 / 20000$ & B. diazoefficiens USDA 110 \\
\hline \multicolumn{8}{|c|}{ RNA processing and modification } \\
\hline 64 & rpsA & $30 S$ ribosomal protein S1 & gi|384214454 & Cytoplasmic & $5.27 / 5.49$ & $62737 / 71000$ & B. japonicum USDA 6 \\
\hline 65 & $\operatorname{rps} A$ & $30 \mathrm{~S}$ ribosomal protein $\mathrm{S} 1$ & gi|27375851 & Cytoplasmic & $5.27 / 5.38$ & $64213 / 70000$ & B. diazoefficiens USDA 110 \\
\hline 66 & $\operatorname{rps} A$ & $30 \mathrm{~S}$ ribosomal protein $\mathrm{S} 1$ & gi|27375851 & Cytoplasmic & $5.27 / 5.31$ & $64213 / 71000$ & B. diazoefficiens USDA 110 \\
\hline 67 & $\operatorname{rps} A$ & $30 S$ ribosomal protein S1 & gi|27375851 & Cytoplasmic & $5.27 / 5.42$ & $64213 / 64000$ & B. diazoefficiens USDA 110 \\
\hline \multicolumn{8}{|c|}{ Transcription } \\
\hline 68 & greA & Transcription elongation factor GreA & gi|27382489 & Cytoplasmic & $5.67 / 6.18$ & $17169 / 20000$ & B. diazoefficiens USDA 110 \\
\hline 69 & rho & Transcription termination factor Rho & gi|27375746 & Cytoplasmic & $6.08 / 6.6$ & $47121 / 45000$ & B. diazoefficiens USDA 110 \\
\hline 70 & rpoA & DNA-directed RNA polymerase alpha subunit & gi|354957001 & Cytoplasmic & $4.91 / 4.97$ & $38082 / 41000$ & B. diazoefficiens USDA 110 \\
\hline 71 & rpoA & DNA-directed RNA polymerase subunit alpha & gi|27380487 & Cytoplasmic & $4.9 / 5.5$ & $38035 / 35000$ & B. diazoefficiens USDA 110 \\
\hline \multicolumn{8}{|c|}{ Cellular processes and signaling } \\
\hline \multicolumn{8}{|c|}{ Posttranslational modification, protein turnover, chaperones } \\
\hline 73 & $C l p B$ & ATP-dependent protease ATP-binding subunit & gi|27376515 & Cytoplasmic & $5.7 / 6.10$ & $96620 / 90000$ & B. diazoefficiens USDA 110 \\
\hline 74 & dnak & Heat shock protein & gi|12642164 & Cytoplasmic & $5.27 / 5.21$ & $65113 / 72000$ & Bradyrhizobium sp. WM9 \\
\hline 75 & $h t p G$ & Heat shock protein 90 & gi|27382900 & Cytoplasmic & $5.08 / 5.16$ & $69004 / 72000$ & B. diazoefficiens USDA 110 \\
\hline 76 & $h t p G$ & Heat shock protein 90 & gi|27382900 & Cytoplasmic & $5.08 / 5.19$ & $69004 / 710000$ & B. diazoefficiens USDA 110 \\
\hline 77 & groEL & Molecular chaperone GroEL & gi|27377170 & Cytoplasmic & $5.19 / 5.32$ & $57749 / 65000$ & B. diazoefficiens USDA 110 \\
\hline 78 & groEL & Molecular chaperone GroEL & gi|27380737 & Cytoplasmic & $5.45 / 5.75$ & $57716 / 58000$ & B. diazoefficiens USDA 110 \\
\hline 79 & tig & Trigger factor & gi|27380056 & Cytoplasmic & $4.87 / 5.06$ & $50061 / 57000$ & B. diazoefficiens USDA 110 \\
\hline 80 & tig & Trigger factor & gi|27380056 & Cytoplasmic & $4.87 / 4.97$ & $50061 / 64000$ & B. diazoefficiens USDA 110 \\
\hline 81 & $c l p X$ & ATP-dependent protease ATP-binding subunit ClpX & gi|27380054 & Cytoplasmic & 5.575 .80 & $46932 / 44000$ & B. diazoefficiens USDA 110 \\
\hline 82 & & Anti-oxidant protein & gi|27380419 & Cytoplasmic & $6.1 / 6.66$ & $24420 / 29000$ & B. diazoefficiens USDA 110 \\
\hline 84 & grpE & Heat shock protein GrpE & gi|27375787 & Cytoplasmic & $4.84 / 4.84$ & $21642 / 27000$ & B. diazoefficiens USDA 110 \\
\hline 85 & Pcm & Protein-L-isoaspartate O-methyltransferase & gi|27379583 & Cytoplasmic & $5.95 / 5.93$ & $25182 / 27000$ & B. diazoefficiens USDA 110 \\
\hline \multicolumn{8}{|c|}{ Cell cycle control, cell division, chromosome partitioning } \\
\hline 86 & $f t s Z$ & Cell division protein FtsZ & gi|27381707 & Periplasmic & $5.21 / 5.40$ & $62990 / 72000$ & B. diazoefficiens USDA 110 \\
\hline \multicolumn{8}{|c|}{ Signal transduction mechanisms } \\
\hline 88 & & Two-component response regulator $\mathrm{OmpR}$ & gi|27377311 & Cytoplasmic & $5.69 / 6.07$ & 26233/29000 & B. diazoefficiens USDA 110 \\
\hline
\end{tabular}


Table 1 Identified proteins of Bradyrhizobium diazoefficiens CPAC 7 whole cell extract and classification according to COG (Continued)

\begin{tabular}{|c|c|c|c|c|c|c|c|}
\hline \multicolumn{8}{|c|}{ Poorly characterized } \\
\hline \multicolumn{8}{|c|}{ General function prediction only } \\
\hline 89 & ychF & GTP-dependent nucleic acid-binding protein EngD & gi|27382550 & Cytoplasmic & $5.13 / 5.22$ & $39493 / 42000$ & B. diazoefficiens USDA 110 \\
\hline 90 & cobs & Cobalt insertion protein & gi|383768898 & Cytoplasmic & $5.62 / 5.80$ & $37304 / 39000$ & Bradyrhizobium sp. S23321 \\
\hline 91 & & Dehydrogenase & gi|27378316 & Cytoplasmic & $5.92 / 6.32$ & $33290 / 38000$ & B. diazoefficiens USDA 110 \\
\hline 93 & $\operatorname{cin} A$ & Competence-damage associated protein & gi|27380722 & Cytoplasmic & $5.29 / 5.51$ & $26451 / 28000$ & B. diazoefficiens USDA 110 \\
\hline \multicolumn{8}{|c|}{ NO related COG } \\
\hline 96 & nusA & Transcription elongation factor NusA & gi|27375896 & Cytoplasmic & $4.70 / 4.77$ & $59333 / 67000$ & B. diazoefficiens USDA 110 \\
\hline 97 & & ATP-dependent phosphoenolpyruvate carboxykinase & gi|398824719 & Cytoplasmic & $6.01 / 6.34$ & $59235 / 62000$ & Bradyrhizobium sp. YR681 \\
\hline 98 & & $\mathrm{ABC}$ transporter substrate-binding protein & gi|27380707 & Periplasmic & $6.93 / 6.00$ & $59019 / 58000$ & B. diazoefficiens USDA 110 \\
\hline 100 & $t / d D$ & TldD protein & gi|27376279 & Cytoplasmic & 5.516 .00 & $51101 / 51000$ & B. diazoefficiens USDA 110 \\
\hline 102 & & $A B C$ transporter substrate-binding protein & gi|27382938 & Periplasmic & $5.57 / 5.66$ & $47774 / 42000$ & B. diazoefficiens USDA 110 \\
\hline 104 & $g l p X$ & Fructose 1,6-bisphosphatase ॥ & gi|27379474 & Cytoplasmic & $5.68 / 6.06$ & $35603 / 4000$ & B. diazoefficiens USDA 110 \\
\hline 104 & & Substrate-binding protein & gi|27382959 & Periplasmic & $6.93 / 5.35$ & $40839 / 41000$ & B. diazoefficiens USDA 110 \\
\hline 105 & ilve & Ketol-acid reductoisomerase & gi|384216635 & Cytoplasmic & $6.09 / 6.70$ & $37076 / 38000$ & B. diazoefficiens USDA 110 \\
\hline 106 & & Dioxygenase & gi|27377910 & Cytoplasmic & $5.35 / 5.58$ & $34110 / 35000$ & B. diazoefficiens USDA 110 \\
\hline 111 & & ATP-dependent Clp protease proteolytic subunit & gi|338974245 & Cytoplasmic & $5.97 / 6.32$ & $22404 / 26000$ & B. diazoefficiens USDA 110 \\
\hline
\end{tabular}

"Theoretical and "**xperimental.

Matched peptides masses and MS/MS combined results are available at the Additional file 1: Table S1. 
Table 2 Functional prediction of hypothetical proteins identified in Bradyrhizobium diazoefficiens CPAC 7 whole protein extract based on protein sequences, conserved domains and motifs, protein-protein interactions and cellular locations

\begin{tabular}{|c|c|c|c|c|c|c|}
\hline Spot ID & Hypothetical protein & NCBI ID & Cellular location & $* \mathrm{~T} / * * \mathrm{E} \mathrm{pl}$ & ${ }^{*} \mathrm{~T} /{ }^{* *} \mathrm{E} \mathrm{MW}$ & Predicted function \\
\hline \multicolumn{7}{|c|}{ Metabolism } \\
\hline \multicolumn{7}{|c|}{ Amino acid transport and metabolism } \\
\hline 25 & Blr3064 & gi|27378175 & Cytoplasmic & $5.64 / 6.00$ & $50837 / 49000$ & $\begin{array}{l}\text { Succinyl-diaminopimelate desuccinylase (COG/NCBI); } \\
\text { Peptidase family M20 - dimerisation domain (Pfam); } \\
\text { GO: Hydrolase activity (InterPro); Lysine biosynthesis } \\
\text { EC:3.5.1.18 (KEGG). }\end{array}$ \\
\hline 30 & Blr5678 & gi|27380789 & Periplasmic & $5.84 / 5.11$ & $33744 / 27000$ & $\begin{array}{l}\text { L-aminopeptidase/D-esterase (COG); Peptidase } \\
\text { family S58 (Pfan); GO:arginine biosynthetic process; } \\
\text { DmpA/ArgJ- Like domains (InterPro). }\end{array}$ \\
\hline
\end{tabular}

Coenzyme transport and metabolism

\begin{tabular}{|c|c|c|c|c|c|}
\hline 36 & Blr3798 & gi|27378909 & Cytoplasmic & $5.66 / 6.13$ & $27452 / 29000$ \\
\hline & Bll4565 & gil27379676 & Cytoplasmic & $5.3 / 5.59$ & $24885 / 28000$ \\
\hline
\end{tabular}

Demethylmenaquinone methyltransferase (COG);

Methyltransf 6 (Pfam):GO: methyltransferase activity

(UniProtKB); Ribonuclease E inhibitor RraA domain (InterPro).

Demethylmenaquinone methyltransferase (COG);

Methyltransf_6 (Pfam);GO: methyltransferase

activity (UniProtKB); Ribonuclease E inhibitor

RraA domain (InterPro).

Information storage and processing

Transcription

72

BII4752

gi|27379863

Cytoplasmic

$4.41 / 4.43$

$27960 / 32000$

Predicted transcriptional regulator containing the HTH domain (COG); Putative transcriptional regulators (Ypuh-like)(Pfam); Winged helix-turn-helix DNA-binding domain (InterPro).

\section{Cellular processes and signaling}

Posttranslational modification, protein turnover, chaperones

83

BJ6T_08050***

gi|354953419

Cytoplasmic

$4.46 / 4.43$

$20515 / 28000$

Thioredoxin-like proteins and domains(COG); Scaffold protein Nfu/NifU N terminal (Pfam):

GO: Iron-sulfur cluster binding (InterPro).

Signal transduction mechanisms
87
Blr2761

gi|27377872

Cytoplasmic

5.465 .70

$29257 / 33000$

Universal stress protein UspA (COG); Universal stress protein family (Pfam): GO: response to stress (InterPro).

\section{Poorly characterized}

General function prediction only 
Table 2 Functional prediction of hypothetical proteins identified in Bradyrhizobium diazoefficiens CPAC 7 whole protein extract based on protein sequences, conserved domains and motifs, protein-protein interactions and cellular locations (Continued)

\begin{tabular}{|c|c|c|c|c|c|c|}
\hline \multicolumn{7}{|c|}{ Function unknown } \\
\hline 94 & Blr5067 & gi|27380178 & Cytoplasmic & $5.25 / 5.29$ & $24247 / 29000$ & $\begin{array}{l}\text { Uncharacterized ACR (COG); putative metal binding } \\
\text { site - region_name = "LabA (NCBI); NYN domain (Pfam). }\end{array}$ \\
\hline 95 & Blr5067 & gi|27380178 & Cytoplasmic & $5.93 / 5.96$ & $16852 / 28000$ & $\begin{array}{l}\text { Uncharacterized ACR (COG); putative metal binding site - } \\
\text { region_name = "LabA (NCBI); NYN domain (Pfam). }\end{array}$ \\
\hline \multicolumn{7}{|c|}{ NO related COG } \\
\hline 99 & Bll0565 & gi|27375676 & Periplasmic & $4.98 / 5.04$ & $41554 / 57000$ & No related data \\
\hline 101 & Blr7534 & gi|27382645 & Periplasmic & $5.86 / 4.99$ & $49518 / 45000$ & No related data \\
\hline 107 & Bll5131 & gi|27380242 & Extracellular & $7.68 / 5.80$ & $34214 / 32000$ & Protein of unknown function DUF (Pfam/InterPro). \\
\hline 108 & Blr2961 & gi|27378072 & Cytoplasmic & $4.96 / 5.06$ & $25510 / 29000$ & $\begin{array}{l}\text { GO: catalytic activity/Metabolic process (InterPro); } \\
\text { Protein of unknown function (Pfam). }\end{array}$ \\
\hline 109 & Bl15307 & gi|27380418 & Periplasmic & $5.55 / 5.70$ & $14177 / 25000$ & No related data \\
\hline 110 & Blr2191 & gi|27377302 & Cytoplasmic & $6.58 / 6.12$ & $25491 / 27000$ & $\begin{array}{l}\text { Uncharacterized protein conserved in bacteria (DUF2328) } \\
\text { (Pfam). KO: chpT histidine phosphotransferase (KEGG); } \\
\text { Two-component system/His Kinase A (phospho-acceptor) } \\
\text { domain (IMG). }\end{array}$ \\
\hline 112 & Bll7551 & gi|27382662 & Cytoplasmic & $5.95 / 5.92$ & $27565 / 26000$ & No related data \\
\hline 113 & Blr0227 & gi|27375338 & Periplasmic & $5.17 / 5.29$ & $22619 / 25000$ & $\begin{array}{l}\text { PHB accumulation regulatory domain (Pfam);GO: } \\
\text { Regulation of transcription/Transcription repressor } \\
\text { activity (NCBI/InterPro). }\end{array}$ \\
\hline 114 & Blr0227 & gi|27375338 & Periplasmic & $5.17 / 6.40$ & $22619 / 24000$ & $\begin{array}{l}\text { PHB accumulation regulatory domain (Pfam);GO: } \\
\text { Regulation of transcription/Transcription repressor } \\
\text { activity (NCBI/InterPro). }\end{array}$ \\
\hline 115 & Blr7436 & gi|27382547 & Cytoplasmic & $4.82 / 4.90$ & 15290/18000 & No related data \\
\hline
\end{tabular}

"Theoretical and ${ }^{* *}$ Experimental.

***Best match with Bradyrhizobium japonicum USDA 6.

Matched peptides masses and MS/MS combined results are available at the Additional file 1: Table S1. 


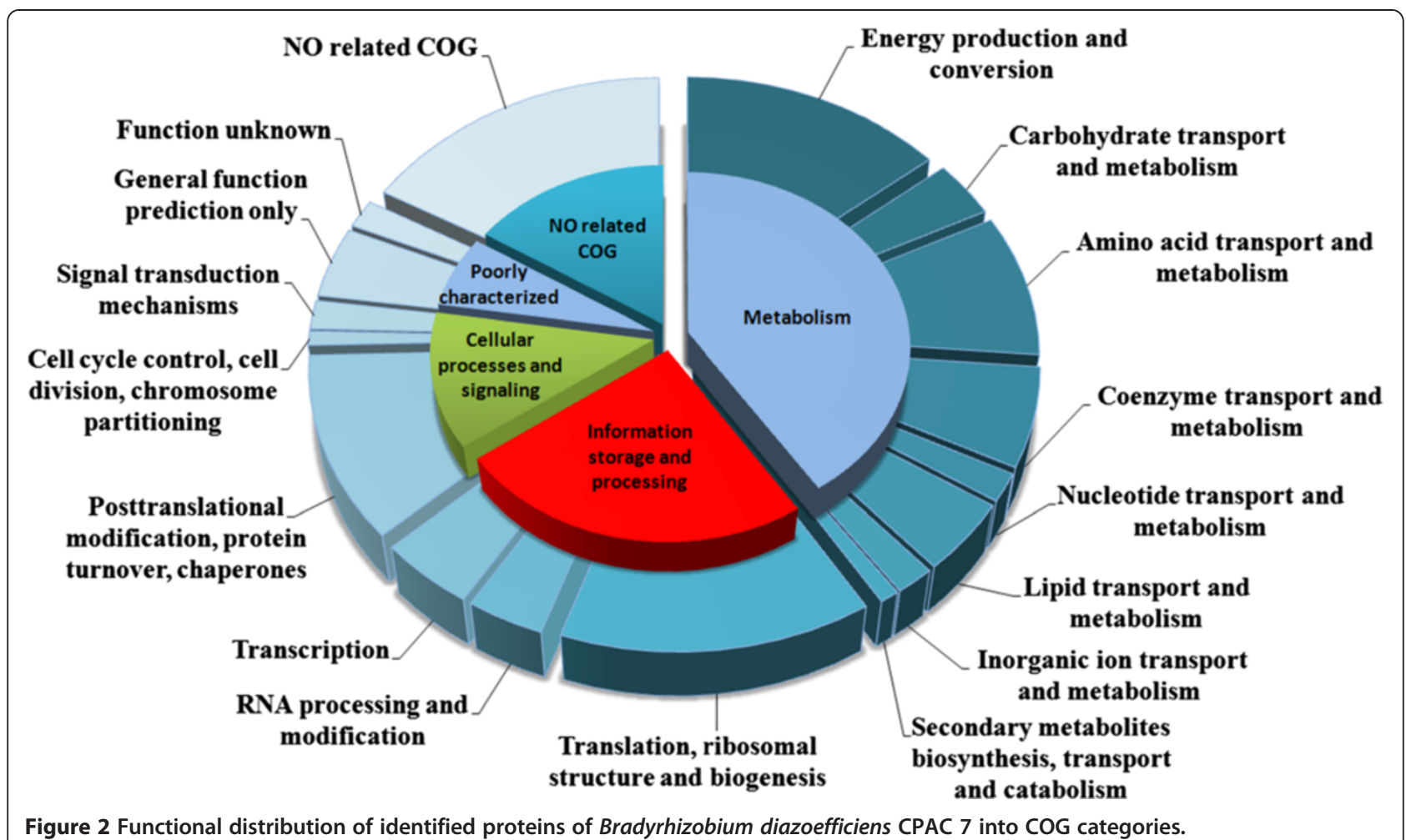

Also important to the production of an effective $\mathrm{N}_{2}$ fixing symbiosis, the exopolysaccharides (EPSs) play an essential role in the symbiotic interaction with compatible host plants $[35,36]$. We found one inositol monophosphatase (IMPase) (Table 1); this protein has been related with the regulation of EPS production, which, when mutated in Rhizobium leguminosarum bv. trifolii, resulted in defective-EPS production and a non- $\mathrm{N}_{2}$-fixing phenotype [37-39].

Several microbial factors, classified either as general or host-specific elicitors, are related to the induction of immune responses in plants [40,41]. General elicitors include flagellins, cold-shock proteins (CSPs), LCOs and LPSs. We identified the elongation factor $\mathrm{Tu}(\mathrm{EFTu})$, which also acts as elicitor and, in general, is conserved across multiple groups of bacteria, allowing plants to perceive and respond to an epitope common to many bacteria $[42,43]$.

In response to general bacterial elicitors, plants have basal defense mechanisms that include increases in extracellular $\mathrm{pH}$, ethylene production, and synthesis of reactive oxygen species (ROSs) [40]. Upon an initial "unfriendly" reception from the host plant, rhizobia must avoid host defenses, and elicit a successful environment to establish an effective $\mathrm{N}_{2}$-fixing symbiosis [44-46]. Among the several features presented by the bacteria to overcome plant defenses, GTP-binding protein TypA, which confers resistance to certain antimicrobial peptides and survival under stress conditions, has been recognized as the main contributor to a successful interaction between Sinorhizobium (=Ensifer) meliloti and some Medicago truncatula lines [44]. A probable symbiotic function of this protein was also observed in B. japonicum CPAC 15 in response to the host flavonoid genistein [47], and now its constitutive expression has been detected in B. diazoefficiens CPAC 7.

The reduction of $\mathrm{N}_{2}$ to ammonia by the nitrogenase complex can take place either by the rhizobial bacteroids inside the nodules, or in free-living rhizobia, including some Bradyrhizobium strains. In both cases, a finely balanced regulation of oxygen availability is required, since rhizobia are aerobic and need oxygen, whereas the element can denature nitrogenase. Inside the nodule, the ideal oxygen environment is reached by the participation of multiple factors, including the synthesis of heme compounds by the rhizobia [48,49]. Proteins $\mathrm{HemB}$ and $\mathrm{HemH}$, identified in CPAC 7 (Table 1), catalyze two important steps in heme synthesis and are essential for the Bradyrhizobium/soybean symbiosis, since mutants defective in these genes generate a microaerobic condition with poorly developed nodules that are inefficient in fixing $\mathrm{N}_{2}[48,50]$.

A protein related to amino acid metabolism and also key in $\mathrm{N}_{2}$ fixation is the glutamine synthetase I (GS I), which was identified in our proteomic map (Table 1). The role of GS I in the regulation of nitrogenase has been highlighted by studies with Rhizobium sp. mutants, resulting in defective ability to derepress the enzyme, both in vitro [51] and in symbiotic conditions [52]. 
In our study, we also detected the constitutive expression of a sigma-54 modulation protein, which fitted in the translation, ribosomal structure and biogenesis functional category (Table 1). Similarly to NifA, this protein participates in controlling the expression of sigma-54 (RpoN, NtrA), which, in turn, helps initiate the transcription of genes encoding proteins for diverse cell functions [53,54]. Among several roles, RpoN is directly involved in the $\mathrm{N}_{2}$-fixation process, being required for control of major $\mathrm{N}_{2}$-fixation genes, as nifHDK, the products of which constitute the nitrogenase complex and accessory proteins [55]. RpoN is also related to free-living metabolic pathways, as demonstrated when rhizobia rpoN-mutants showed, beyond defects in symbiotic $\mathrm{N}_{2}$-fixation [56], alterations in free-living nitrate assimilation [57]. We may suppose that the constitutive sigma-54 modulation protein may be important in mediating adaptations to changing environmental conditions, both in free-living and in symbiotic conditions.

The expression of the key protein NifH (nitrogenase iron protein, or component II) in our study may be related to the presence of sigma-54 modulation protein, which was shown to be a regulator of the sigma-54 expression. To support this, results show that the knockout of sigma54 transcriptional factor in B. japonicum leads to strong pleiotropic effects, including the absence of NifH [57] and the abolishment of symbiotic $\mathrm{N}_{2}$-fixation ability [55]. The detection of $\mathrm{NifH}$ in our proteomic study might correlate with reports of expression of nitrogenase in Bradyrhizobium strains under free-living conditions; however, measurements of nitrogenase activity under these conditions are difficult and require a fine adjustment of the oxygen concentration [58-61].

\section{Stress-tolerance proteins}

In tropical regions, crops and soil microorganisms are frequently exposed to stressful conditions, in particular high temperatures, salinity and soil acidity $[6,62,63]$. Therefore, in addition to high efficiency of $\mathrm{N}_{2}$ fixation, commercial rhizobial strains must be tolerant of such adverse factors. Indeed, several soybean bradyrhizobia have been extensively studied to characterize their tolerances of salt [64], desiccation [65], antibiotics [66], acidity [67], among other stresses. Now, in B. diazoeficiens CPAC 7 we produced evidence of several molecular determinants related to the ability to overcome adverse conditions, including chaperonins and other proteins, such as Clp proteases and transcription-elongation factors, with roles in cell defense.

ATP-dependent Clp proteases participate in diverse cell processes, including rapid adaptive responses of bacteria to environmental changes [29] and to stressful conditions [30], and ClpB and ClpX were detected in CPAC 7. These two proteins have the properties associated with molecular chaperones, such as preventing the aggregation of denatured proteins and, in some cases, refolding them [68].
These properties are particularly important under stress conditions that exacerbate the occurrence of protein denaturation, and $\mathrm{ClpB}$ and $\mathrm{ClpX}$ help to ensure a fast return to the pre-stressed state, maintaining cell homeostasis $[69,70]$.

Bradyrhizobium is acid-tolerant, it grows at $\mathrm{pH} 4.5$, over $30 \%$ of the strains are capable of growing at $\mathrm{pH} 4.0$ and a few are tolerant of $\mathrm{pH} 3.5$ [71]. The proteome of $B$. diazoefficiens USDA 110, when studied at $\mathrm{pH} 4.7$ [72], revealed differential expression of several proteins, eight of which-spots $5,8,15,49,70,81,82$, and 91-were constitutively expressed in the proteome of CPAC 7 (Table 1).

Another limiting factor for rhizobia, and also for the symbiosis, is high soil temperature, which can often exceed $40^{\circ} \mathrm{C}$ in the tropics and limit the success of inoculants $[6,8,62]$. Rhizobia, similar to most organisms [73], make use of molecular chaperones to tolerate high temperatures, including heat-shock proteins (HSPs) DnaK, GrpE, GroEL and HtpG, which were identified in our proteomic reference map (Table 1). DnaK and GrpE comprise a versatile chaperone system [74] that, together with GroEL and HtpG, play a critical role in thermotolerance, routinely rescuing the majority of the proteins denatured [69,75].

Still associated with thermotolerance, it is worth mentioning the identification of three elongation factors (Ef-Tu, Ef-Ts and Ef-G) and two ribosomal proteins (30S and 50S) expressed in CPAC 7. Besides their main function of ensuring gene expression, elongation factors can also act as chaperones [26,27]. This secondary role has been demonstrated recently at the proteomic level in Rhizobium tropici strain PRF 81 (now reclassified as Rhizobium freirei) under hightemperature stress [75]. In B. japonicum, $30 \mathrm{~S}$ and $50 \mathrm{~S}$ ribosomal proteins may be involved in heat-stress defense, once they were up-regulated at $43^{\circ} \mathrm{C}$ [76]. Considering this finding, those authors hypothesized that ribosomes may act as sensors of heat shock in B. japonicum. A similar mechanism has been suggested in $E$. coli, in which ribosomes seem to be the primary sensor of conditions that evoke heatshock responses [77].

Oxidative stress is frequently caused by cell exposure to reactive oxygen species (ROSs), such as superoxide anion $\left(\mathrm{O}_{2}^{-}\right)$and hydrogen peroxide $\left(\mathrm{H}_{2} \mathrm{O}_{2}\right)$. ROSs are byproducts of normal metabolic processes and, if not properly detoxified, they become toxic. Oxidative stress also occurs by cell exposure to external ROSs, which in bacteria such as rhizobia may take place during interactions with other microorganisms or eukaryotic hosts. Therefore, tolerating and overcoming oxidative stress is critical to bacteria viability as well as for the establishment of a successful symbiotic infection [32,78].

Of the proteins identified in CPAC 7, at least five have already been reported as showing antioxidant activity (spots 16, 50, 68, 82 and 83, Table 1). Among them, ferredoxin-NADP ${ }^{+}$reductase $(\mathrm{FRN})$ has been reported to 
overcome the harmful effects of ROSs on DNA replication [79]. Those authors emphasized the importance of FRN to cell protection against oxidative damage by comparing its role with those of superoxide dismutases, a group of proteins well known for mitigating damage caused by ROSs.

Salinity leads to loss of intracellular water, resulting in osmotic disturbances that can influence a range of metabolic activities [80]. Indeed, several negative effects in rhizobia-plant symbioses have been attributed to salinity; e.g. in growth and survival of rhizobia in soil, in root colonization and in nodule development [81].

Mutational studies with $S$. meliloti allowed the identification of multiple genes involved in salt tolerance, including trigger factor (tig) [82]. When this gene was absent, Sinorhizobium showed reduced ability to grow in LB with high salt concentrations, as well inability to compete against the wild-type for nodule occupancy [82]. Given these results, we suggest that tig may also contribute to competitiveness and to saprophytic competence under environmentally stressful conditions, as reported for CPAC $7[7,8,10,11,22]$.

Classified in the information storage and processing COG category, the transcription elongation factor GreA has been recognized as a general stress protein (Gsp) induced in response to various environmental conditions. Additionally to the transcription elongation activity, its role in acid-, salt-, and cold-stress responses in Streptococcus mutans [83], S. meliloti [84] and R. tropici [85] has been reported. Constitutive expression of GreA was previously reported in a B. japonicum CPAC 15 proteomic assay [23]. Mutation of greA in $R$. tropici impaired the establishment of an effective symbiosis as a result of the altered ability to adapt to hyperosmosis and salt stress [85], highlighting the importance of this protein in overcoming adverse conditions during symbiosis establishment.

Altogether, these bacterial defense mechanisms are crucial to survival in the soil and to symbiosis establishment in the tropics, where rhizobia are commonly exposed to high soil temperatures, acid $\mathrm{pH}$ and saline conditions $[3,8]$.

\section{Hypothetical proteins: function prediction with bioinformatics tools}

In several genome projects, portions of the annotated sequences have been classified in "hypothetical", "conserved hypothetical" or "of unknown function" categories $[86,87]$. These denominations are used when the existence of a gene is supported only by prediction of gene-finding software, and they do not show significant homology to any characterized gene [23]. With B. diazoefficiens USDA 110, these proteins were abundant, and, of the 8,317 proteincoding genes predicted, $30 \%$ showed similarity to hypothetical genes, whereas $18 \%$ showed no similarity to any registered gene [13]; in the genome of CPAC 7, both categories comprised $50 \%$ of all predicted genes [20]. A still modest improvement in annotation of hypothetical proteins has been achieved with proteomic studies $[23,87]$. For example, the reference map of B. japonicum CPAC 15 contributed to the assignment of 26 hypothetical proteins by using bioinformatics tools [23].

In our study, 20 proteins were classified as hypothetical/ conserved hypothetical or unknown, and by using bioinformatics tools, we were able to attribute probable functions to half of them (Table 2). Two proteins (Blr3064 and Blr5678) were assigned to the amino acid transport and metabolism COG category. The first one shows hydrolase activity and, according to the KEGG database, participates in lysine biosynthesis. Blr5678 is probably related to the arginine biosynthetic process, since it has an ArgJ-like domain.

Classified according to the COGnitor in the coenzyme transport and metabolism functional category, proteins Blr3798 and Bll4565, represented by spots 36 and 37 (Figure 1, Table 2) presented similar information in the databanks searched in our study. Both were annotated as demethylmenaquinone methyltransferase by COG and exhibited a ribonuclease $\mathrm{E}$ inhibitor RraA domain. The inhibitory activity of this domain was recently described in E. coli as having a regulatory function in gene expression, since the interactions of RraA with RNase E affect the composition of the RNA-degradosome, modulating its activity $[88,89]$.

The cytoplasmic protein Bll4752, which belongs to the transcriptional COG group is predicted as a transcriptional regulator protein that contains a Ypuh-like helixturn-helix domain (Table 2). This protein probably plays a role in chromosomal partitioning during cell division.

BJ6T_08050, classified in the posttranslational modification, protein turnover, chaperones functional category, shows $97 \%$ of similarity with Bll0800 of B. diazoefficiens USDA 110. After comparison of databases, this hypothetical protein was assigned as a thioredoxin-like protein involved in iron transport (Table 2); however, it may be related to reactivation of proteins damaged by oxidative stress [90]. Also potentially related to cell defense, Blr2761 is closely similar to universal stress protein UspA, expression of which is known to be enhanced when cells are exposed to adverse conditions [91].

Two other proteins constitutively expressed in strain CPAC 7-Bll5663 and Blr5067-remained annotated as hypothetical in the NCBInr database (Table 2). Bll5663 is a member of the MoxR family of AAA + ATPases, widespread among bacteria. Associated with diverse cellular activities, MoxR ATPases display a chaperone-like function and have been found to be important modulators of multiple-stress-response pathways in various organisms, including $R$. leguminosarum [92,93]. The other protein, Blr5067, was also expressed in bacteroids of $B$. diazoefficiens USDA 110, and is still poorly characterized [14]; it could be a LabA-like protein with a putative 
metal-binding site. This family of proteins has been studied in cyanobacteria and reported to affect both gene expression and cellular metabolic state [94,95]. Nevertheless, the biological role of Blr5067 in Bradyrhizobium remains to be determined.

\section{Genistein effect on the expression of hypothetical protein-coding genes}

Ten out of the 20 hypothetical proteins identified in our proteomic study did not fit into any of the functional categories of COG, being assigned as "NO related COG" (Table 2). The lack of homology of these sequences with those of known proteins, combined with their detection at the proteomic level, suggest that they could be interesting subjects of study, possibly providing new information and deeper understanding of the organism. We analyzed the relative expression patterns of nine hypothetical proteincoding genes (two spots-113 and 114-showed similarity with the same protein Blr0227) in response to genistein. The localization of the genes encoding these proteins in the genome of $B$. diazoefficiens CPAC 7 is shown in Additional file 1: Table S1. Identified as one of the main components present in soybean root extract [96], genistein induces the expression of nod genes in Bradyrhizobium [16,97]. In addition, it has been shown that flavonoids, such as genistein, can induce the expression of other genes besides nod genes $[15,47]$.

The product of nodC directs the synthesis of the backbone of lipochitin oligosaccharides (LCOs), also called Nod factors, which are essential for the nodulation process [97-100]. In our study, the nodC gene of CPAC 7 was used as a positive control in the RT-qPCR analysis, and upregulation was confirmed; in addition, six of the nine hypothetical protein-encoding genes were significantly up-regulated (Figure 3). Of these, bll0565 and blr2961 protein-coding genes showed the highest genisteininduction effect, and up-regulation was observed also for blr7534, bll5307, blr2191 and blr0227.

Blr2191 is a ChpT histidine phosphotransferase, well characterized in Caulobacter crescentus, a model organism in cell-cycle studies [101]; in this bacterium, the protein controls, via phosphorylation, the activity of the master cell-cycle regulator CtrA [102,103]. The role of histidine phosphotransferases in the cell cycle of $B$. diazoefficiens is still to be elucidated; however, with the results from our study-showing its induction by genistein-we may suppose that it affects the growth rate of $B$. diazoefficiens in a genistein-enriched environment, such as the soybean rhizosphere [104].

Protein Blr0227 has also been identified in B. japonicum under neutral [23] and acidic conditions [72]. A potential implication of this protein in rhizobial competitiveness might exist, since it is up-regulated in response to the flavonoid daidzein in B. japonicum strain 4534, a strain highly competitive for nodulation, but not in the poorly competitive B. japonicum strain 4222 [105]; it is noteworthy that CPAC 7 is also competitive. Blr0227 has a polyhydroxybutyrate (PHB)-accumulation regulatory domain and it is known that in B. japonicum large amounts of carbon are directed to the synthesis of storage compounds, especially PHB [106]. Interestingly, the PHB biosynthesis also seems to be associated with rhizosphere competitiveness, since B. japonicum mutants defective in PHB synthesis show reduced competitiveness [107].

Three out of the nine proteins of CPAC 7 analyzed were not significantly induced by genistein, Bll5131, Bll7551 and Blr7436 (Figure 3, Additional file 2: Figure S1), confirming results reported with $B$. japonicum strain CPAC 15 [47]. They may play other roles, e.g. Bll7551 was one of the up-regulated proteins in bacteroids of B. japonicum



Figure 3 Expression levels of hypothetical proteins coding genes of Bradyrhizobium diazoefficiens strain CPAC 7 after growth to exponential phase in the presence of genistein. Relative expression was determined by REST2009 software. 
USDA 110 [108], suggesting a role in latter steps in the development of the symbiosis.

\section{Conclusions}

CPAC 7 is an agronomically important strain used in commercial inoculants for application to soybean crops in Brazil and in other South American countries; it presents high $\mathrm{N}_{2}$-fixation efficiency, and adaptability to tropical conditions $[7,8,11,109]$. Here we provide the first proteomic map for this bacterium, revealing molecular determinants of distinct steps in the establishment and functioning of the symbiotic biological $\mathrm{N}_{2}$-fixation process. We also report the constitutive expression of proteins such as DnaK, ferredoxin-NADP ${ }^{+}$ reductase (FRN) and trigger factor (tig) related to cell protection against heat-, oxidative- and salt stress conditions, that should contribute to bacterial survival and symbiotic functioning under adverse environmental conditions common in the tropics. In general, no function can be attributed to more than one third of the putative genes in bacterial genomes. With the approach taken in our study-including proteomics, use of bioinformatics tools and transcriptomic assays-it was possible to obtain information about several hypothetical genes/proteins of $B$. diazoefficiens, revealing interesting information, with an emphasis on genistein-induced genes, that deserve further study to confirm their roles in the soybean root-nodule symbiosis.

\section{Methods}

\section{Strain and culture conditions}

Bradyrhizobium diazoefficiens strain CPAC 7 (=SEMIA 5080, =CNPSo 6), a natural variant of CB 1809 (=USDA 136 , a subculture of USDA 122) $[10,110]$ is used in commercial inoculants in Brazil since 1992 [7]. Information about morpho-physiologic, genetic and symbiotic properties is available elsewhere [10,11,111-113]. CPAC 7 is deposited at the "Diazotrophic and Plant Growth Promoting Bacteria Culture Collection" of Embrapa Soja (WFCC Collection \# 1213, WDCC Collection \# 1054).

The strain was pre-cultured in $10-\mathrm{mL}$ aliquots of arabinose-gluconate (AG) medium [114], at $80 \mathrm{rpm}$ and $28^{\circ} \mathrm{C}$, in the dark. For the proteomic experiment, precultures were transferred to Erlenmeyer flasks containing $200 \mathrm{~mL}$ of the same medium and were grown under the same conditions as for the pre-cultures until the exponential phase (O.D. of 0.6 at $600 \mathrm{~nm})$. Low agitation $(80 \mathrm{rpm})$ was employed to minimize the production of extracellular polysaccharides, which can interfere with the 2-D gel electrophoresis.

For the reverse transcription quantitative PCR (RTqPCR), pre-cultures were transferred to Erlenmeyer flasks containing $100 \mathrm{~mL}$ of AG medium. Bacteria were grown to the exponential phase under two treatment conditions: induced or not with genistein $(5 \mu \mathrm{M}$, final concentration) dissolved in methanol, added as $50 \mu \mathrm{L}$ per $100 \mathrm{~mL}$ of culture [15]; to the non-induced cultures, the same amount of methanol was added. In both proteomics and qPCR experiments, bacteria were grown in triplicates for each treatment.

\section{Whole-cell protein extraction}

Cultures were centrifuged at 5,000 g, at $4^{\circ} \mathrm{C}$ and cells were carefully washed with a solution containing $3 \mathrm{mM} \mathrm{KCl}$; $1.5 \mathrm{mM} \mathrm{KH} \mathrm{PO}_{4} ; 68 \mathrm{mM} \mathrm{NaCl}$; and $9 \mathrm{mM} \mathrm{NaH} \mathrm{PO}_{4}$. Washed cells were resuspended in $600 \mu \mathrm{L}$ of a buffer containing $10 \mathrm{mM}$ Tris- $\mathrm{HCl} \mathrm{pH} 8.0 ; 1.5 \mathrm{mM} \mathrm{MgCl}$; $10 \mathrm{mM}$ $\mathrm{KCl}$; $0.5 \mathrm{mM}$ DTT; and 0.5 mM PMSF. Aliquots of $150 \mu \mathrm{L}$ were stored in ultrafreezer $\left(-80^{\circ} \mathrm{C}\right)$ until the analyses.

For total protein extraction, aliquots were resuspended in lysis buffer (9.5 M urea; 2\% CHAPS; 0.8\% v/v Pharmalyte 4-7; and 1\% DTT), and submitted to forty cycles of freezing in liquid $\mathrm{N}_{2}$ and thawing at $37^{\circ} \mathrm{C}$, as described before [115]. The lysates were separated from particulate material by centrifugation at $14,000 \mathrm{~g}$ for $90 \mathrm{~min}$, at $4^{\circ} \mathrm{C}$. Protein extract was washed with phenol and the concentration was determined by NanoDrop 1000 Spectrophotometer V3.7 (Thermo Scientific).

\section{Two-dimensional gel electrophoresis and visualization}

For isoelectric focusing (IEF), $300 \mu \mathrm{g}$ of protein extract were dissolved with DeStreak buffer (GE Healthcare) and $2 \% \mathrm{v} / \mathrm{v}$ IPGphor to a final volume of $250 \mu \mathrm{L}$. IPG-strips ( $\mathrm{pH} 4-7,13 \mathrm{~cm}, \mathrm{GE}$ Healthcare) were rehydrated overnight with the protein solution and covered with Cover Fluid (GE Healthcare). Loaded strips were submitted to isoelectric focalization in an Ettan IPGphor IEF system (GE Healthcare) for $1 \mathrm{~h}$ at $200 \mathrm{~V}, 1 \mathrm{~h}$ at $500 \mathrm{~V}$, a gradient step to $1,000 \mathrm{~V}$ for $1 \mathrm{~h}$, a gradient step to $8,000 \mathrm{~V}$ for $2 \mathrm{~h}$ $30 \mathrm{~min}$, and fixed at $8,000 \mathrm{~V}$ for $1 \mathrm{~h} 30 \mathrm{~min}$. The final $\mathrm{Vh}$ was fixed at 24,800 . Prior to second dimension,, strips were equilibrated first for $20 \mathrm{~min}$ in $5 \mathrm{~mL}$ of an equilibration buffer (50 mM Tris- $\mathrm{HCl} \mathrm{pH} \mathrm{8.8;} 6 \mathrm{M}$ urea; 30\% v/v glycerol; $2 \% \mathrm{w} / \mathrm{v}$ SDS; and $0.2 \% \mathrm{v} / \mathrm{v}$ of a $1 \%$ solution of bromophenol blue) supplemented with $50 \mathrm{mg}$ DTT and then in TE buffer with $175 \mathrm{mg}$ of iodoacetamine, also for $20 \mathrm{~min}$.

The second dimension electrophoresis was performed in a $12 \%$ polyacrylamide gel in a Ruby SE 600 vertical electrophoresis system (GE Healthcare). The run was carried out for $30 \mathrm{~min}$ at $15 \mathrm{~mA} / \mathrm{gel}$ and $240 \mathrm{~min}$ at $30 \mathrm{~mA} /$ gel, using the Low Molecular Weight Calibration Kit for SDS Electrophoresis (Amersham Biosciences) as standard. Similarly to the protein extraction step, both dimensions of gel electrophoresis were run in triplicate. Gels were fixed overnight with an ethanol-acetic acid solution before being stained with Coomassie Blue PhastGel ${ }^{\mathrm{Tm}} \mathrm{R}-350$ (GE Healthcare) and were then scanned (ImageScanner LabScan v5.0). 


\section{Gel image analysis and sample preparation to mass spectrometry}

Protein spots were automatically detected in the highresolution digitized gel images and analyzed by Image Master 2D Platinum v 5.0 software (GE Healthcare). Well defined spots were manually selected, excised and processed as previously described [116]. Digestion was achieved with trypsin (Gold Mass Spectrometry Grade, Promega, Madison, WI) at $37^{\circ} \mathrm{C}$, overnight.

Peptides from digested proteins were mixed with saturated solution of $\alpha$-cyano- 4-hydroxy-cinnamic acid (HCCA) in 50\% acetonitrile, $0.1 \%$ trifluoroacetic acid (TFA). The mixture was spotted onto a MALDI (Matrix Assisted Laser Desorption Ionization) target plate and allowed to crystallize at room temperature. The same procedure was used for the standard peptide calibration mixture I (Bruker Daltonics). For mass spectra acquisition, a MALDI-TOF-TOF (MALDI-time-of-flight in tandem) UltraFlex III mass spectrometer (Bruker Daltonics) was operated in the reflector for MALDI-TOF MS peptide mass fingerprint (PMF) and in the "LIFT" mode for MALDI-TOF-TOF MS/MS fragmentation experiments, on fully manual mode using FlexControl software v. 2.2. To process the data obtained, Flex Analysis v.3.0 software (Bruker Daltonics, Billerica, MA) was employed.

\section{Protein identification}

PMFs and MS/MS ion spectra generated were searched against the public database NCBInr (National Center for Biotechnology Information non-redundant), using Mascot software search engine v. 2.3 (http://www.matrixscience. $\mathrm{com} /$ ). For protein searches, performed in the Proteobacteria taxonomic group, monoisotopic masses were used, considering a peptide tolerance of $150 \mathrm{ppm}$ and allowance of one missed cleavage. When MS/MS was carried out, a tolerance of $0.3 \mathrm{Da}$ was acceptable. Carbamidomethylation of cysteine and oxidation of methionine were considered fixed and variable modifications, respectively.

Identifications were validated only when the Mowse (molecular weight search) score was significant. Searches on the Decoy database (Mascot) were done and both decoy score and false discovery rates were considered for the identification. The spectrometry datasets are available at the Additional file 1: Table S1.

\section{In silico protein characterization}

A set of bioinformatics tools was used to improve the characterization of the proteins. The proteins were fitted into COG (Clusters of Orthologous Groups) categories according to their functional inference, using the COGnitor program (http://www.ncbi.nih.gov/COG) [117]. Software packages PSORT-B [118] and PSLpred [119] were used for the prediction of subcellular localization.
To search for putative roles of the hypothetical proteins, a package of bioinformatics tools was applied [87]. SignalP [120] was employed for the prediction of signal peptides. To determine the protein family and domains we used Pfam [121] and InterPro [122]. MicrobesOnline (http://www.microbesonline.org) [123], a suite of webbased comparative tools, and the Integrated Microbial Genomes system (http://img.jgi.doe.gov) [124] were also searched. Finally, the prediction of physical and functional protein interactions was carried out with STRING 9.1 (http://string-db.org/) [125].

\section{RNA extraction and primers design}

Cells from $35 \mathrm{~mL}$ of the control and the genistein induced bacterial cultures (item 2.1) were centrifuged $(8,000 \mathrm{~g}$ for $10 \mathrm{~min}$ at $4^{\circ} \mathrm{C}$ ) and the pellet was resuspended in $280 \mu \mathrm{g}$ of lysis buffer, consisted of $250 \mu \mathrm{L}$ of TE (10 mM Tris, adjusted to $\mathrm{pH} 8.0$ with $\mathrm{HCl} ; 1 \mathrm{mM}$ EDTA), $10 \mu \mathrm{L}$ of lysozyme $(5 \mathrm{mg} / \mathrm{mL})$ and $20 \mu \mathrm{L}$ of $10 \%$ SDS solution $(\mathrm{w} / \mathrm{v})$. After resuspended, the mixture was incubated at $37^{\circ} \mathrm{C}$ for $5 \mathrm{~min}$ to achieve an efficient cell disruption. Lysates were then centrifuged $\left(8,000 \mathrm{~g}\right.$ for $10 \mathrm{~min}$ at $\left.4^{\circ} \mathrm{C}\right)$ and the supernatants were transferred to new 2-mL tubes and homogenized with $1 \mathrm{~mL}$ of $\mathrm{TRIzol}^{\oplus}$ reagent (Life Technologies). This new mixture was centrifuged and the superior phase was transferred to another tube. After a wash step with chloroform, RNA was precipitated by adding $500 \mu \mathrm{L}$ of cold isopropanol, purified with RNeasy Mini Kit (Quiagen) and quantified by NanoDrop ND-1000 (NanoDropTechnologies, Inc.). The RNA was assessed in a $1 \%(\mathrm{w} / \mathrm{v})$ agarose gel.

Primers were designed using PrimerExpress 3.0 (Applied Biosystems/Life Technologies, Grand Island, NY, USA) targeting an amplicon size of 50-200 bp. The primer sequences were searched against the $B$. diazoefficiens strain USDA 110 genome (http://www.ncbi.nlm.nih.gov/genome/18384) to verify their specificity. Primer sequences and amplification efficiency rates are shown in Additional file 3: Table S2.

Extracted RNAs were submitted to DNAse treatment (Invitrogen/Life Technologies, Grand Island, NY, USA), and high quality total RNA was used to synthesize cDNA strands (Superscript II First Strand Synthesis, Invitrogen/Life Technologies, Grand Island, NY, USA).

\section{Relative gene expression analysis by RT-qPCR}

After carrying out the amplification to determine the primers efficiency rate, nine hypothetical genes were amplified by RT-qPCR using a 7500 RT-qPCR Thermocycler (Applied Biosystems/Life Technologies, Grand Island, NY, USA) with the following manufacturer's instructions: $50^{\circ} \mathrm{C}$ for $2 \mathrm{~min}, 95^{\circ} \mathrm{C}$ for $10 \mathrm{~min}, 45$ cycles at $95^{\circ} \mathrm{C}$ for $2 \mathrm{~min}$, $60^{\circ} \mathrm{C}$ for $30 \mathrm{~s}$ and $72^{\circ} \mathrm{C}$ for $30 \mathrm{~s}$, in 45 cycles. The $16 \mathrm{~S}$ rRNA gene was used as endogenous control (Additional file 3: Table S2). 
Rest2009 software package [126] was used to evaluate the data by providing a robust statistical analysis (Additional file 2: Figure S1). The normalization of cycle threshold $(\mathrm{Ct})$ of RT-qPCR amplifications was performed based on the selected endogenous gene (16S rRNA). The genistein responsive gene $\operatorname{nod} C$ [127] was used as positive control.

\section{Additional file}

Additional file 1: Table S1. Complementary information about protein identifications. All searches were performed with Mascot software v. 2.3 (http://www.matrixscience.com/) against the public database NCBInr (National Center for Biotechnology Information non-redundant). *Identified by MS; **Identified by MS/MS.

Additional file 2: Figure S1. Localization in the genome of $B$. diazoefficiens CPAC 15 of the genes coding hypothetical proteins used in our study.

Additional file 3: Table S2. Statistical results of RT-qPCR data provided by Rest2009 software package.

\section{Competing interests}

The authors declare that they have no competing interests.

\section{Authors' contributions}

Conceived and designed the experiments: MH, LVGT Performed the experiments: DFG, JSSB, AAPR, LPS, CB Analyzed the data: DFG, JSSB, AAPR, LPS, CB, LVGT, MH Contributed reagents/materials/analysis tools: $M H, L P S, C B$ Wrote the paper: DFG, JSSB, LPS, MH. All authors read and approved the final manuscript.

\section{Acknowledgements}

The study was partially supported by CNPq (National Council for Scientific and Technological Development), Project Repensa (562008/2010-1) and Science without Borders (400205/2012-5). Authors acknowledge Dr. Allan R.J. Eaglesham for suggestions on the manuscript and English review. D.F.G. acknowledges a PhD fellowship from Project Repensa and J.S.S.B was and A.A.P.R. postdoc fellowships from CNPq. M.H. is also a research fellow from CNPq. Approved for publication by the Editorial Board of Embrapa Soja as manuscript 12/2014.

\section{Author details}

${ }^{1}$ Embrapa Soja, Embrapa Soja, C.P. 231, 86001-970 Londrina, Paraná, Brazil. 2Departamento de Genética, Universidade Federal do Paraná, C.P. 19031, 81531-900 Curitiba, PR, Brazil. ${ }^{3}$ Present address: Departamento de Biologia Estrutural, Molecular e Genética, Universidade Estadual de Ponta Grossa, C.P. 6001, 84030-900 Ponta Grossa, PR, Brazil. Embrapa Recursos Genéticos e Biotecnologia, PqEB s/nº, 70770-901 Brasília, DF, Brazil.

Received: 5 May 2014 Accepted: 25 July 2014

Published: 3 August 2014

\section{References}

1. Saravanan VS, Madhaiyan M, Osborne J, Thangaraju M, Sa TM: Ecological occurrence of Gluconacetobacter diazotrophicus and nitrogen-fixing Acetobacteraceae members: their possible role in plant growth promotion. Microb Ecol 2008, 55:130-140.

2. Graham PH, Vance CP: Legumes: importance and constraints to greater use. Plant Physiol 2003, 13:872-877.

3. Ormeño-Orrillo E, Menna P, Almeida LGP, Ollero FJ, Nicolás MF, Rodrigues EP, Nakatani AS, Batista JSS, Chueire LMO, Souza RC, Vasconcelos ATR, Megías M, Hungria M, Martínez-Romero E: Genomic basis of broad host range and environmental adaptability of Rhizobium tropici CIAT 899 and Rhizobium sp. PRF 81 which are used in inoculants for common bean (Phaseolus vulgaris L.). BMC Genomics 2012, 13:735.

4. Vance CP: Update on the state of nitrogen and phosphorus nutrition symbiotic nitrogen fixation and phosphorus acquisition: plant nutrition in a world of declining renewable resources. Plant Physiol 2001, 127:390-397.
5. Subramanian S, Smith DL: A proteomics approach to study Soybean and its symbiont Bradyrhizobium japonicum - A Review. In Agricultural and Biological Sciences, A Comprehensive Survey of International Soybean Research - Genetics, Physiology, Agronomy and Nitrogen Relationships". CC BY 3.0 license. Edited by Board JE. 2013:3-30.

6. Hungria M, Andrade DDS, Chueire LMO, Probanza A, Guttierrez FJM, Megías M: Isolation and characterization of new eficient and competitive bean (Phaseolus vulgaris L.) rhizobia from Brazil. Soil Biol Bioche 2000, 32:1515-1528.

7. Hungria M, Franchini JC, Campo RJ, Crispino CC, Moraes JZ, Sibaldelli RNR, Mendes IC, Arihara J: Nitrogen nutrition of soybean in Brazil: contributions of biological $\mathrm{N}_{2}$ fixation and $\mathrm{N}$ fertilizer to grain yield. Can J Plant Sci 2006, 86:927-939.

8. Hungria $M$, Vargas MAT: Environmental factors affecting $\mathrm{N}_{2}$ fixation in grain legumes in the tropics, with an emphasis on Brazil. Field Crops Res 2000, 65:151-164.

9. Hungria M, Mendes $I C$ : Nitrogen fixation with soybean: the perfect symbiosis? In Biol nitrogen Fixat. Edited by de Bruijn F. Hoboken: Wiley-Blackwell. New Jersey, Wiley Publisher; 2014.

10. Delamuta JRM, Ribeiro RA, Ormeño-Orrillo E, Melo IS, Martínez-Romero E, Hungria M: Polyphasic evidence supporting the reclassification of Bradyrhizobium japonicum group la strains as Bradyrhizobium diazoefficiens sp. nov. Int J Syst Evol Microbiol 2013, 63:3342-3351.

11. Hungria $M$, Boddey $L H$, Santos MA, Vargas MAT: Nitrogen fixation capacity and nodule occupancy by Bradyrhizobium japonicum and B. elkanii strains. Biol Fertil Soils 1998, 27:393-399.

12. Ferreira MC, Hungria M: Recovery of soybean inoculant strains from uncropped soils in Brazil. Field Crops Res 2002, 79:139-152.

13. Kaneko T, Nakamura Y, Sato S, Minamisawa K, Uchiumi T, Sasamoto S, Watanabe A, Idesawa K, Iriguchi M, Kawashima K, Kohara M, Matsumoto M, Shimpo S, Tsuruoka H, Wada T, Yamada M, Tabata S: Complete genomic sequence of nitrogen-fixing symbiotic bacterium Bradyrhizobium japonicum USDA110. DNA Res 2002, 9:225-256.

14. Sarma AD, Emerich DW: Global protein expression pattern of Bradyrhizobium japonicum bacteroids: a prelude to functional proteomics. Proteomics 2005, 5:4170-4184.

15. Süss C, Hempel J, Zehner S, Krause A, Patschkowski T, Göttfert M: Identification of genistein-inducible and type III-secreted proteins of Bradyrhizobium japonicum. J Biotechnol 2006, 126:69-77.

16. Lang K, Lindemann A, Hauser F, Göttfert M: The genistein stimulon of Bradyrhizobium japonicum. Mol Genet Genomics 2008, 279:203-211.

17. Wei M, Yokoyama T, Minamisawa K, Mitsui H, Itakura M, Kaneko T, Tabata S, Saeki K, Omori H, Tajima S, Uchiumi T, Abe M, Ohwada T: Soybean seed extracts preferentially express genomic loci of Bradyrhizobium japonicum in the initial interaction with soybean, Glycine $\max (\mathrm{L}$.) Merr. DNA Res 2008, 15:201-214

18. Hempel J, Zehner S, Göttfert M, Patschkowski T: Analysis of the secretome of the soybean symbiont Bradyrhizobium japonicum. J Biotechnol 2009, 140:51-58.

19. Delmotte N, Ahrens CH, Knief C, Qeli E, Koch M, Fischer H-M, Vorholt JA Hennecke $H$, Pessi G: An integrated proteomics and transcriptomics reference data set provides new insights into the Bradyrhizobium japonicum bacteroid metabolism in soybean root nodules. Proteomics 2010, 10:1391-1400.

20. Siqueira AF, Ormeño-Orrillo E, Souza RC, Rodrigues EP, Almeida LGP, Barcellos FG, Batista JSS, Nakatani AS, Martínez-Romero E, Vasconcelos ATR Hungria M: Comparative genomics of Bradyrhizobium japonicum CPAC 15 and Bradyrhizobium diazoefficiens CPAC 7: elite model strains for understanding symbiotic performance with soybean. BMC Genomics 2014, 15:420.

21. Gupta N, Tanner S, Jaitly N, Adkins JN, Lipton M, Edwards R, Romine M, Osterman A, Bafna V, Smith RD, Pevzner PA: Whole proteome analysis of post-translational modifications: Applications of mass-spectrometry for proteogenomic annotation. Gen Res 2007, 17:1362-1377.

22. Ansong C, Purvine SO, Adkins JN, Lipton MS, Smith RD: Proteogenomics: needs and roles to be filled by proteomics in genome annotation. Brief Funct Genomic Proteomic 2008, 7:50-62

23. Batista JSS, Torres AR, Hungria M: Towards a two-dimensional proteomic reference map of Bradyrhizobium japonicum CPAC 15: spotlighting "hypothetical proteins". Proteomics 2010, 10:3176-3189.

24. Yadav AS: Auxotrophy in rhizobia revisited. Indian J Microbiol 2007, $47: 279-288$ 
25. Santos MF, Pádua VLM, Nogueira EM, Hemerly AS, Domont GB: Proteome of Gluconacetobacter diazotrophicus co-cultivated with sugarcane plantlets. J Proteomics 2010, 73:917-931.

26. Caldas TD, El Yaagoubi A, Richarme G: Chaperone properties of bacterial elongation factor EF-Tu. J Bio/ Chem 1998, 273:11478-11482.

27. Caldas T, Laalami S, Richarme G: Chaperone properties of bacterial elongation factor EF-G and initiation factor IF2. J Biol Chem 2000, 275:855-860.

28. Wagner MA, Zahrl D, Rieser G, Koraimann G: Growth phase- and cell division-dependent activation and inactivation of the $\sigma 32$ regulon in Escherichia coli. J Bacteriol 2009, 191:1695-1702.

29. Gaillot O, Bregenholt S, Jaubert F, Santo JPDI, Berche P: Stress-induced clpp serine protease of listeria monocytogenes is essential for induction of listeriolysin o-dependent protective immunity. Infect Immun 2001, 69:4938-4943.

30. Gerth U, Krüger E, Derré I, Msadek T, Hecker M: Stress induction of the Bacillus subtilis ClpP gene encoding a homologue of the proteolytic component of the Clp protease and the involvement of ClpP and ClpX in stress tolerance. Mol Microbiol 1998, 28:787-802.

31. Cai SJ, Inouye M: EnvZ-OmpR interaction and osmoregulation in Escherichia coli. J Biol Chem 2002, 277:24155-24161.

32. Gomes DF, Batista JSDS, Torres AR, Andrade DS, Galli-Terasawa LV, Hungria M: Two-dimensional proteome reference map of Rhizobium tropici PRF 81 reveals several symbiotic determinants and strong resemblance with agrobacteria. Proteomics 2012, 12:859-863.

33. van Rhijn P, Vanderleyden J: The Rhizobium-plant symbiosis. Microbio/ Rev 1995, 59:124-142

34. Geiger O, López-Lara IM: Rhizobial acyl carrier proteins and their roles in the formation of bacterial cell-surface components that are required fo the development of nitrogen-fixing root nodules on legume hosts. FEMS Microbiol Lett 2002, 208:153-162

35. Parniske M: ExoB Mutants of Bradyrhizobium japonicum with reduced competitiveness for nodulation of Glycine max. Mol Plant-Microbe Interact 1993, 6:99.

36. Becker BU, Kosch K, Parniske M, Müller P: Exopolysaccharide (EPS) synthesis in Bradyrhizobium japonicum: sequence, operon structure and mutational analysis of an exo gene cluster. Mol Gen Genet 1998, 259:161-171.

37. Janczarek M, Skorupska A: Exopolysaccharide synthesis in Rhizobium leguminosarum bv. trifolii is related to various metabolic pathways. Res Microbiol 2003, 154:433-442.

38. Janczarek M, Skorupska A: Regulation of $p s s A$ and $p s s B$ gene expression in Rhizobium leguminosarum bv. trifolii in response to environmental factors. Antonie Van Leeuwenhoek 2004, 85:217-227.

39. Janczarek M, Król J, Skorupska A: The pssB gene product of Rhizobium leguminosarum bv. trifolii is homologous to a family of inositol monophosphatases. FEMS Microbiol Lett 1999, 173:319-325.

40. Jones KM, Kobayashi H, Davies BW, Taga ME, Walker GC: How rhizobial symbionts invade plants: the Sinorhizobium-Medicago model. Nat Rev Microbiol 2007, 5:619-633.

41. Abramovitch RB, Anderson JC, Martin GB: Bacterial elicitation and evasion of plant innate immunity. Nat Rev Mol Cell Biol 2006, 7:601-611.

42. Boller T: Peptide signalling in plant development and self/non-self perception. Curr Opin Cell Biol 2005, 17:116-122.

43. Zeidler D, Zähringer U, Gerber I, Dubery I, Hartung T, Bors W, Hutzler P, Durner J: Innate immunity in Arabidopsis thaliana: lipopolysaccharides activate nitric oxide synthase (NOS) and induce defense genes. Proc Natl Acad Sci U S A 2004, 101:15811-15816.

44. Kiss $\mathrm{E}$, Huguet $\mathrm{T}$, Poinsot $\mathrm{V}$, Batut J: The typA gene is required for stress adaptation as well as for symbiosis of Sinorhizobium meliloti 1021 with certain Medicago truncatula lines. Mol Plant Microbe Interact 2004, 17:235-244.

45. Goebel W, Gross R: Intracellular survival strategies of mutualistic and parasitic prokaryotes. Trends Microbiol 2001, 9:267-273.

46. van Sluys MA, Monteiro-Vitorello CB, Camargo LE, Menck CFM, Da Silva AC, Ferro JA, Oliveira MC, Setubal JC, Kitajima JP, Simpson AJ: Comparative genomic analysis of plant-associated bacteria. Annu Rev Phytopathol 2002, 40:169-189.

47. Batista JSS, Hungria M: Proteomics reveals differential expression of proteins related to a variety of metabolic pathways by genistein-induced Bradyrhizobium japonicum strains. J Proteomics 2012, 75:1211-1219.
48. Chauhan S, O'Brian MR: Transcriptional regulation of delta-aminolevulinic acid dehydratase synthesis by oxygen in Bradyrhizobium japonicum and evidence for developmental control of the hemB gene. J Bacteriol 1997, 179:3706-3710.

49. Page KM, Guerinot ML: Oxygen control of the Bradyrhizobium japonicum hemA gene. J Bacteriol 1995, 177:3979-3984

50. Frustaci JM, Brian MRO: Characterization of a Bradyrhizobium japonicum ferrochelatase mutant and isolation of the hemH gene. J Bacteriol 1992, 174:4223-4229.

51. Ludwig RA, Signer ER: Glutamine synthetase and control of nitrogen fixation in Rhizobium. Nature 1977, 267:245-248.

52. Kondorosi A, Svfib Z, Kiss GB, Dixon RA: Ammonia assimilation and nitrogen fixation in Rhizobium meliloti. Mol Gen Genet 1977, 226:221-226.

53. Dombrecht B, Marchal K, Vanderleyden J, Michiels J: Prediction and overview of the RpoN-regulon in closely related species of the Rhizobiales. Genome Biol 2002, 3. research0076.1-0076.11.

54. Shingler V: Signal sensing by sigma 54-dependent regulators: derepressionas a control mechanism. Mol Microbiol 1996, 19:409-416.

55. Fischer HM: Genetic regulation of nitrogen fixation in rhizobia. Microbiol Rev 1994, 58:352-386.

56. Clark SR, Oresnik IJ, Hynes MF: RpoN of Rhizobium leguminosarum bv. viciae strain VF39SM plays a central role in FnrN-dependent microaerobic regulation of genes involved in nitrogen fixation. Mol Gen Genet 2001, 264:623-633.

57. Kullik I, Fritsche S, Knobel H, Sanjuan J, Hennecke H, Fischer HM: Bradyrhizobium japonicum has two differentially regulated, functional homologs of the sigma 54 gene (rpoN). J Bacteriol 1991, 173:1125-1138.

58. Alazard D: Nitrogen fixation in pure culture by rhzobia isolated from stem nodules of tropical Aeschynomene species. FEMS Microbiol Lett 1990, 68:177-182.

59. Kurz WGW, Larue TA: Nitrogenase activity in rhizobia in absence of plant host. Nature 1975, 256:407-409.

60. Pankhurst CE, Scott DB, Ronson CW: Correlation between rifampicinresistance of slow-growing Rhizobium strains and their ability to express nitrogenase activity in culture. FEMS Microbiol Lett 1982, 15:137-139.

61. Agarwal AK, Keister DL: Physiology of ex planta nitrogenase activity in Rhizobium japonicum. Appl Environ Microbiol 1983, 45:1592-1601.

62. Martínez-Romero E, Segovia L, Mercante FM, Franco AA, Graham P, Pardo MA Rhizobium tropici, a novel species nodulating Phaseolus vulgaris L. beans and Leucaena sp. trees. Int J Syst Bacteriol 1991, 41:417-426.

63. Graham PH, Draeger KJ, Ferrey ML, Conroy MJ, Hammer BE, Martinez E, Aarons SR, Quinto C: Acid pH tolerance in strains of Rhizobium and Bradyrhizobium, and initial studies on the basis for acid tolerance of Rhizobium tropici UMR1899. Can J Microbiol 1994, 40:198-207.

64. Barboza F, Correa NS, Rosas SB: Metabolic and physiological characteristics of salt-tolerant strains of Bradyrhizobium spp. Biol Fertil Soils 2000, 32:368-373

65. Mary P, Dupuy N, Dolhembiremon C, Defives C, Tailliez R: Differences among Rhizobium meliloti and Bradyrhizobium japonicum strains in tolerance to desiccation and storage at different relative humidities. Soil Biol Biochem 1994, 26:1125-1132.

66. Raza S, Jørnsgård B, Abou-Taleb H, Christiansen JL: Tolerance of Bradyrhizobium sp. (Lupini) strains to salinity, $\mathrm{pH}, \mathrm{CaCO}_{3}$ and antibiotics. Lett Appl Microbiol 2001, 32:379-383.

67. Asanuma S, Ayanaba A: Variation in acid-al tolerance of Bradyrhizobium japonicum strains from African soils. Soil Sci Plant Nutr 1990, 36:309-317.

68. Wawrzynow A, Wojtkowiak D, Marszalek J, Banecki B, Jonsen M, Graves B, Georgopoulos C, Zylicz M: The ClpX heat-shock protein of Escherichia coli, the ATP-dependent substrate specificity component of the ClpP-ClpX protease, is a novel molecular chaperone. EMBO J 1995, 14:1867-1877.

69. Thomas JG, Baneyx F: ClpB and HtpG facilitate de novo protein folding in stressed Escherichia coli cells. Mol Microbiol 2000, 36:1360-1370.

70. Yu AYH: Investigation of ClpXP protease mechanism of function and its interaction with the folding chaperone trigger factor by. PhD thesis. University of Toronto; 2013

71. Jordan DC, Bacteriology D: Transfer of Rhizobium japonicum Buchanan 1980 to Bradyrhizobium gen. nov., a genus of slow-growing, root nodule bacteria from leguminous plants. Int J Syst Bacterio/ 1982, 32:136-139.

72. Puranamaneewiwat N, Niamsup H: Proteomic analysis of Bradyrhizobium japonicum USDA110 in acidic condition. Chiang Mai J Sci 2006, 33:335-345. 
73. Gupta RS: Evolution of the chaperonin families (Hsp60, Hsp10 and Tcp-1) of proteins and the origin of eukaryotic cells. Mol Microbiol 1995, 15:1-11.

74. Hartl FU, Hayer-Hartl M: Converging concepts of protein folding in vitro and in vivo. Nat Struct Mol Biol 2009, 16:574-581.

75. Gomes DF, Batista JSS, Schiavon AL, Andrade DS, Hungria M: Proteomic profiling of Rhizobium tropici PRF 81: identification of conserved and specific responses to heat stress. BMC Microbiol 2012, 12:84.

76. Münchbach $M$, Dainese $P$, Staudenmann W, Narberhaus F, James P: Proteome analysis of heat shock protein expression in Bradyrhizobium japonicum. Eur J Biochem 1999, 264:39-48.

77. VanBogelen RA, Neidhardt FC: Ribosomes as sensors of heat and cold shock in Escherichia coli. Proc Natl Acad Sci U S A 1990, 87:5589-5593.

78. Seaver LC, Imlay JA, Loewen P: Alkyl hydroperoxide reductase is the primary scavenger of endogenous hydrogen peroxide in Escherichia coli. J Bacteriol 2001, 183:7173-7181.

79. Krapp R, Division MB, Molecular B: The role of ferredoxin-NADP' reductase in the concerted cell defense against oxidative damage - studies using Escherichia coli mutants and cloned plant genes. Eur J Biochem 1997, 563:556-563.

80. Challougui Fatnassi I, Harzalli Jebara S, Jebara M: Selection of symbiotic efficient and high salt-tolerant rhizobia strains by gamma irradiation. Ann Microbiol 2010, 61:291-297.

81. Kulkarni S, Surange S, Nautiyal CS: Crossing the limits of Rhizobium existence in extreme conditions. Curr Microbiol 2000, 41:402-409.

82. Miller-Williams M, Loewen PC, Oresnik IJ: Isolation of salt-sensitive mutants of Sinorhizobium meliloti strain Rm1021. Microbiology 2006, 152(Pt 7):2049-2059.

83. Lena CL: Stress-responsive proteins are upregulated in Streptococcus mutans during acid tolerance. Microbiology 2004, 150:1339-1351.

84. Wei W, Jiang J, Li X, Wang L, Yang SS: Isolation of salt-sensitive mutants from Sinorhizobium meliloti and characterization of genes involved in salt tolerance. Lett Appl Microbiol 2004, 39:278-283.

85. Nogales J, Campos R, BenAbdelkhalek H, Olivares J, Lluch C, Sanjuan J: Rhizobium tropici genes involved in free-living salt tolerance are required for the establishment of efficient nitrogen-fixing symbiosis with Phaseolus vulgaris. Mol Plant Microbe Interact 2002, 15:225-232.

86. Minion FC, Lefkowitz EJ, Madsen ML, Cleary BJ, Swartzell SM, Mahairas GG: The genome sequence of Mycoplasma hyopneumoniae strain 232, the agent of wwine mycoplasmosis. J Bacterio/ 2004, 186:7123-7133.

87. Lubec G, Afjehi-Sadat L, Yang J-W, John JPP: Searching for hypothetical proteins: theory and practice based upon original data and literature. Prog Neurobiol 2005, 77:90-127.

88. Pietras Z, Tsai Y, Callaghan AJ, Herna H: The regulatory protein RraA modulates RNA-binding and helicase activities of the $E$. coli RNA degradosome. RNA 2010, 16:553-562

89. Pandey SP, Minesinger BK, Kumar J, Walker GC: A highly conserved protein of unknown function in Sinorhizobium meliloti affects sRNA regulation similar to Hfq. Nucleic Acids Res 2011, 39:4691-4708.

90. Fernando MR, Nanri H, Yoshitake S, Nagata-Kuno K, Minakami S: Thioredoxin regenerates proteins inactivated by oxidative stress in endothelial cells. Eur J Biochem 1992, 209:917-922.

91. Freestone $P$, Nyström $T$, Trinei $M$, Norris $V$ : The universal stress protein UspA, of Escherichia coli is phosphorylated in response to stasis. J Mol Biol 1997, 274:318-324.

92. Vanderlinde EM, Magnus SA, Tambalo DD, Koval SF, Yost CK: Mutation of a broadly conserved operon (RL3499-RL3502) from Rhizobium leguminosarum biovar viciae causes defects in cell morphology and envelope integrity. J Bacteriol 2011, 193:2684-2694.

93. Wong KS, Houry WA: Novel structural and functional insights into the MoxR family of AAA + ATPases. J Struct Biol 2012, 179:211-221.

94. Taniguchi Y, Katayama M, Ito R, Takai N, Kondo T, Oyama T: IabA: a novel gene required for negative feedback regulation of the cyanobacterial circadian clock protein KaiC. Genes Dev 2007, 21:60-70.

95. Taniguchi $Y$, Nishikawa T, Kondo T, Oyama T: Overexpression of IalA, a paralog of $l a b A$, is capable of affecting both circadian gene expression and cell growth in the cyanobacterium Synechococcus elongatus PCC 7942. FEBS Lett 2012, 586:753-759.

96. Porter PM, Banwart WL, Hassett JJ: HPLC isolation and GC-MS identification of genistein, daidzein, and coumestrol from unhydrolyzed soybean root extracts. Environ Exp Bot 1985, 25:229-232.
97. Kosslak RM, Bookland R, Barkei J, Paaren HE, Appelbaum ER: Induction of Bradyrhizobium japonicum common nod genes by isoflavones isolated from Glycine max. Proc Natl Acad Sci U S A 1987, 84:7428-7432.

98. Hungria M, Stacey G: Molecular signals exchanged between host plants and rhizobia: basic aspects and potential application in agriculture. Soil Biol Biochem 1997, 29:819-830.

99. Debellé F, Mou L, Mangin B, Dénarié J, Boivin C: Nod ggenes and Nod signals and the evolu tion of the Rhizobium legume symbiosis. Acta Biochim Pol 2001, 48:359-365.

100. Brencic A, Winans SC, Colonization P: Detection of and response to signals involved in host-microbe interactions by plant-associated bacteria. Microbiol Mol Biol Rev 2005, 69:155-194.

101. Purcell EB, Boutte CC, Crosson S: Two-component signaling systems and cell cycle control in Caulobacter crescentus. Adv Exp Med Biol 2008, 631:122-130.

102. Fioravanti A, Clantin B, Dewitte F, Lens Z, Verger A, Biondi EG, Villeret V: Structural insights into $\mathrm{ChpT}$, an essential dimeric histidine phosphotransferase regulating the cell cycle in Caulobacter crescentus. Acta Crystallogr Sect F: Struct Biol Cryst Commun 2012, 68(Pt 9):1025-1029.

103. Biondi EG, Reisinger SJ, Skerker JM, Arif M, Perchuk BS, Ryan KR, Laub MT: Regulation of the bacterial cell cycle by an integrated genetic circuit. Nature 2006, 444:899-904.

104. Dudeja SS, Khurana AL: Persistence of Bradyrhizobium sp. (Cajanus) in a sandy loam. Soil Biol Biochem 1989, 21:709-713.

105. Li J, Xiao W, Ma M, Guan D, Jiang X, Cao F, Shen D, Chen H, Li L: Proteomic study on two Bradyrhizobium japonicum strains with different competitivenesses for nodulation. Agric Sci China 2011, 10:1072-1079.

106. Lodwig EM, Leonard M, Marroqui S, Wheeler TR, Findlay K, Downie JA, Poole PS: Role of polyhydroxybutyrate and glycogen as carbon storage compounds in pea and bean bacteroids. Mol Plant Microbe Interact 2005, 18:67-74

107. Aneja P, Zachertowska A, Charles TC: Comparison of the symbiotic and competition phenotypes of Sinorhizobium meliloti PHB synthesis and degradation pathway mutants. Can J Microbiol 2005, 51:599-604.

108. Nomura M, Arunothayanan H, Van Dao T, Le HT-P, Kaneko T, Sato S, Tabata S, Tajima S: Differential protein profiles of Bradyrhizobium japonicum USDA110 bacteroid during soybean nodule development. Soil Sci Plant Nutr 2010, 56:579-590.

109. Marks BB, Nogueira MA, Hungria M, Megías M: Biotechnological potential of rhizobial metabolites to enhance the performance of Bradyrhizobium spp. and Azospirillum brasilense inoculants with soybean and maize. AMB Express 2013, 3:21

110. Santos MA, Vargas MA, Hungria M: Characterization of soybean Bradyrhizobium strains adapted to the Brazilian savannas. FEMS Microbio Ecol 1999, 30:261-272

111. Menna P, Barcellos FG, Hungria M: Phylogeny and taxonomy of a diverse collection of Bradyrhizobium strains based on multilocus sequence analysis of the $16 \mathrm{~S}$ rRNA gene, ITS region and $g$ Inll, recA, atpD and dnaK genes. Int J Syst Evol Microbiol 2009, 59(Pt 12):2934-2950.

112. Barcellos FG, Menna P, Batista JSS, Hungria M: Evidence of horizontal transfer of symbiotic genes from a Bradyrhizobium japonicum inoculant strain to indigenous diazotrophs Sinorhizobium (Ensifer) fredii and Bradyrhizobium elkanii in a Brazilian Savannah soil. Appl Environ Microbiol 2007, 73:2635-2643.

113. Barcellos FG, Batista JSS, Menna P, Hungria M: Genetic differences between Bradyrhizobium japonicum variant strains contrasting in N2-fixation efficiency revealed by representational difference analysis. Arch Microbiol 2009, 191:113-122.

114. Sadowsky MJ, Tully RE, Cregan PB, Keyser HH: Genetic diversity in Bradyrhizobium japonicum Sserogroup 123 and its relation to genotypespecific nodulation of soybean. Appl Environ Microbiol 1987, 53:2624-2630.

115. Lery LMS, Coelho A, von Kruger WMA, Gonçalves MSM, Santos MF, Valente RH, Santos EO, Rocha SLG, Perales J, Domont GB, Teixeira KRS, Bertalan M, Ferreira PCG, Bisch PM: Protein expression profile of Gluconacetobacter diazotrophicus PAL5, a sugarcane endophytic plant growth-promoting bacterium. Proteomics 2008, 8:1631-1644.

116. Chaves DFS, Souza EM, Monteiro RA, Pedrosa FO: A two-dimensional electrophoretic profile of the proteins secreted by Herbaspirillum seropedicae strain Z78. J Proteomics 2009, 73:50-56.

117. Tatusov RL, Galperin MY, Natale DA, Koonin EV: The COG database: a tool for genome-scale analysis of protein functions and evolution. Nucleic Acids Res 2000, 28:33-36. 
118. Gardy JL, Laird MR, Chen F, Rey S, Walsh CJ, Ester M, Brinkman FSL: PSORTb v. 2.0: expanded prediction of bacterial protein subcellular localization and insights gained from comparative proteome analysis. Bioinformatics 2005, 21:617-623.

119. Bhasin M, Garg A, Raghava GPS: PSLpred: prediction of subcellular localization of bacterial proteins. Bioinformatics 2005, 21:2522-2524.

120. Bendtsen JD, Nielsen H, von Heijne G, Brunak S: Improved prediction of signal peptides: SignalP 3.0. J Mol Biol 2004, 340:783-795.

121. Bateman A, Birney E, Cerruti L, Durbin R, Etwiller L, Eddy SR, Griffiths-Jones S, Howe KL, Marshall M, Sonnhammer ELL: The Pfam protein families database. Nucleic Acids Res 2002, 30:276-280.

122. Mulder NJ, Apweiler R, Attwood TK, Bairoch A, Bateman A, Binns D, Biswas M, Bradley P, Bork P, Bucher P, Copley R, Courcelle E, Durbin R, Falquet L, Fleischmann W, Gouzy J, Griffith-Jones S, Haft D, Hermjakob H, Hulo N, Kahn D, Kanapin A, Krestyaninova M, Lopez R, Letunic I, Orchard S, Pagni M, Peyruc D, Ponting $C P$, Servant $F$, et al: InterPro: an integrated documentation resource for protein families, domains and functional sites. Brief Bioinform 2002, 3:225-235.

123. Alm EJ, Huang KH, Price MN, Koche RP, Keller K, Dubchak IL, Arkin AP: The microbesOnline web site for comparative genomics. Genome Res 2005 15:1015-1022.

124. Markowitz VM, Korzeniewski F, Palaniappan K, Szeto E, Werner G, Padki A Zhao X, Dubchak I, Hugenholtz P, Anderson I, Lykidis A, Mavromatis K, Ivanova N, Kyrpides NC: The integrated microbial genomes (IMG) system. Nucleic Acids Res 2006, 34:344-348.

125. Jensen $\sqcup$, Kuhn M, Stark M, Chaffron S, Creevey C, Muller J, Doerks T, Julien P, Roth A, Simonovic M, Bork P, von Mering C: STRING 8-a global view on proteins and their functional interactions in 630 organisms. Nucleic Acids Res 2009, 37:412-416.

126. Pfaffl MW, Horgan GW, Dempfle L: Relative expression software tool (REST) for group-wise comparison and statistical analysis of relative expression results in real-time PCR. Nucleic Acids Res 2002, 30:e36.

127. Bortolan $S$, Barcellos FG, Marcelino FC, Hungria M: Expressão dos genes nodC, nodW e nopP em Bradyrhizobium japonicum estirpe CPAC 15 avaliada por RT-qPCR. Pesa Agropec Bras 2009, 44:1491-1498.

doi:10.1186/1471-2164-15-643

Cite this article as: Gomes et al:: Proteomic analysis of free-living Bradyrhizobium diazoefficiens: highlighting potential determinants of a successful symbiosis. BMC Genomics 2014 15:643.

\section{Submit your next manuscript to BioMed Central and take full advantage of:}

- Convenient online submission

- Thorough peer review

- No space constraints or color figure charges

- Immediate publication on acceptance

- Inclusion in PubMed, CAS, Scopus and Google Scholar

- Research which is freely available for redistribution

Submit your manuscript at www.biomedcentral.com/submit
(O) Biomed Central 